\title{
EUROPA Y AMÉRICA. MÚSICA LITÚRGICA EN ÁMBITO HISPÁNICO. LA CATEDRAL DE LAS PALMAS DE GRAN CANARIA Y SU MAESTRO DE CAPILLA DIEGO DURÓN DE ORTEGA $(* 1653 ; \uparrow 1731)$. DOCUMENTACIÓN Y MARCAS DE AGUA
}

\author{
AMERICA AND EUROPE. LITURGICAL MUSIC IN HISPANIC WORLD. \\ CATHEDRAL LAS PALMAS AND ITS MAESTRO \\ DE CAPILLA DIEGO DURON $(* 1653, \dagger 1731)$. \\ DOCUMENTATION AND WATERMARKS
}

Francisco Javier Romero Naranjo

Universidad de Alicante

\begin{abstract}
Resumen
La Capilla Musical de la Catedral de Las Palmas de Gran Canaria posee una historia sumamente interesante al estar compuesta por músicos de diversas nacionalidades y localizarse geográficamente en un lugar estrategico debido a su conexión con el continente americano. Diego Durón de Ortega fue uno de los maestros de Capilla mas representativos y estables que supo afrontar las particularidades de la misma. En esta investigación presentamos una breve documentación sobre la Catedral de Las Palmas de Gran Canaria en relación a la figura de Diego Durón de Ortega y un resumido estudio sobre las marcas de agua de su producción litúrgica conservadas en el archivo de la mencionada catedral.
\end{abstract}

\footnotetext{
Palabras clave

Diego Durón de Ortega, Catedral de Las Palmas de Gran Canaria, Marcas de Agua, policoralidad.
}

The choir of the Cathedral of Las Palmas de Gran Canaria has a fascinating history. This is due to the fact that members are of a range of nationalities and the Cathedral itself is in a strategic geographic location, well linked to America. Diego Durón de Ortega was one of the most emblematic and long-standing chapel masters and knew how to deal with the particular challenges of the Cathedral. In this research, we set out a brief summary of the Cathedral of Las Palmas de Gran Canaria and its link to the figure of Diego Durón de Ortega, as well as a short study on the hallmarks of his liturgical production in the archives of the Cathedral.

Key words

Diego Durón de Ortega, Cathedral of Las Palmas de Gran Canaria, Watermarks, polychoral style.

Abstract 


\section{BREVE INTRODUCCIÓN BIOGRÁFICA SOBRE LA FIGURA DE DIEGO DURÓN.}

El maestro de capilla Diego Durón de Ortega está considerado uno de los compositores más representativos del barroco español, como atestigua L. Siemens, debido a su capacidad creativa tanto en su producción litúrgica como en romance ${ }^{1}$. Hasta el momento no se ha publicado ninguna biografía amplia y específica sobre la figura de Diego Durón $^{2}$ y éste es un aspecto imprescindible, dado que puede ayudar a entender su producción musical en Canarias. Por esta razón he procedido a la realización de una introducción a su biografía con base en las actas capitulares.

Hasta 1963 no se sabía de su existencia y su importancia como maestro de capilla en la catedral de Las Palmas de Gran Canaria. En un principio se le confundía con su hermanastro Sebastián Durón Picazo, hasta que la musicóloga Lola de la Torre averiguó que eran dos personas completamente diferentes ${ }^{3}$.

Diego Durón de Ortega nació en Brihuega, provincia de Guadalajara, en 1653 y antes de los diez años fue internado en el monasterio jerónimo de Lupiana, donde se formó. En 1674 se traslada a Cuenca para perfeccionarse como maestro de capilla, de la mano de Alonso Xuárez, quien en 1676 lo recomendó a la catedral de Las Palmas de Gran Canaria. Su maestro lo consideró un compositor de gran talento y con un gran conocimiento "científico" de la música, por lo que le consideró el más adecuado tras la petición por parte del cabildo de la catedral canaria de un nuevo maestro de capilla ${ }^{4}$.

El nuevo maestro de capilla llega a la isla en 1676 con tan sólo 23 años de edad. A pesar de su juventud, supo enfrentarse correctamente a todos los deberes que su puesto requería, por lo que la capilla de la catedral dio un giro completo tras su magisterio. Este maestro representa la culminación de la capilla de la catedral, ya que realmente creó escuela en la isla, formó alumnos de los que se suministraba

* Mi más profundo agradecimiento a Rosario Álvarez, Lothar Siemens y Hermann Danuser coodirectores directos e indirectos de este pequeño extracto de mi tesis doctoral, presentada en Alemania en la Universidad Alexander von Humboldt de Berlín en 2008.

1 SIEMENS HERNÁNDEZ (1984): 5.

2 Aunque no hay que olvidar las reseñas realizadas en los diccionarios Die Musik Geschichte und Gegenwart, The New Grove Dictionary of Music and Musicians o Diccionario de la Música Española e Hispanoamericana. Los datos más actualizados sobre Diego Durón de Ortega desde el punto de vista biográfico y de su producción en latín y en romance los ha recogido SIEMENS HERNÁNDEZ (1999): vol. 4, $572-575$

3 TORRE CHAMPASUR DE TRUJILLO (1963): 39-49.

4 SIEMENS HERNÁNDEZ (1984): 5-6. la propia capilla, e incluso otros ejercieron su profesión musical en la Península o en las Indias.

Su producción supera las 450 composiciones (tanto en música litúrgica en latín como en villancicos en romance), y fue ésta tan importante, que su música se siguió interpretando hasta el siglo XIX en Gran Canaria.

La única fuente existente en Canarias que narra de forma progresiva los aspectos de la vida de Diego Durón en la catedral de Las Palmas de Gran Canaria son las actas capitulares. Por desgracia, los datos son muy breves, y en ellos mayoritariamente se habla de la llegada y salida de nuevos músicos, el salario que cobran y los préstamos que reciben de la catedral al tener problemas económicos, entre otras cosas.

Esto permite realizar una biografía en cuanto al maestro de capilla Diego Durón a retazos, dado que la información es muy dispersa, y no especifica lo que se debería saber. Por ello, he destacado los aspectos más importantes de cada período de forma cronológica, desde su llegada a Canarias en 1676, hasta su defunción en 1731.

El nuevo maestro de capilla llega a las islas por recomendación de su maestro, el famoso Alonso Xuárez, maestro de capilla de la catedral de Cuenca, el cual recomienda a su discípulo más aventajado Diego Durón, clérigo y compositor ya muy destacado. Durón fue educado desde niño en el monasterio jerónimo de Lupiana, desde donde posteriormente marcha a Cuenca, lugar en el que se encontraba el maestro de capilla Alonso Xuárez, con el fin de aprender de él y sucederle cuando este se fuera a la catedral sevillana. Al quedar vacante la plaza de maestro de capilla en la catedral de Las Palmas de Gran Canaria, los planes originarios de Diego Durón se vieron cambiados, y tuvo que optar entre esperar y ser maestro de capilla en Cuenca, o embarcarse apresuradamente para las Islas Canarias, ya que urgía un maestro para la catedral. De haber marchado a Cuenca, tendría que haber esperado un tiempo hasta que su maestro viera la posibilidad de establecerse como maestro de capilla en Sevilla. De haber sido así, a Diego Durón le hubiese servido el puesto de Cuenca como trampolín para acceder "previo examen" a otras catedrales, además de estar al tanto de la nueva música que se imprimía y de los puestos que quedaban vacantes en la península. La opción de marcharse a Canarias se fundamentaba en su entrada como maestro de capilla sin examen alguno y además con un sueldo muy alto para un maestro de capilla con 23 años y poco experimentado hasta ese momento.

Diego Durón embarca para Gran Canaria el 8 de mayo de 1676 contratado como maestro de capilla de la catedral de Las Palmas de Gran Canaria en 1676, donde se le señala su salario "de trigo", que reza de la siguiente manera: 
“Al memorial de Diego Durón, maestro de capilla de esta santa iglesia, en que pide se le mande acudir con el salario de trigo que le pertenece se acordó se le acuda con dicho salario desde ocho de mayo de este presente año que es desde que embarcó para estas islas" "5.

La labor de Durón en la catedral de Las Palmas de Gran Canaria fue singular, dado que creó una escuela de cantores y músicos con la que poco a poco fue nutriendo la propia catedral, sin tener ya la necesidad de pedirlos a la península como era costumbre. En las actas capitulares de 1677 queda patente este hecho, al interceder el cabildo de la catedral para que así se realice ${ }^{6}$ :

"En este cabildo al memorial del maestro de capilla Diego Durón, en que pide se sirva el cabildo mandar se hagan diligencias por algunos muchachos de buena voz para enseñarlos en cumplimiento a su obligación y que sirvan de tiples y se traslade el libro de las pasiones y se aderesen los demás de música que se necesiten, conferidos por todo el cabildo se acordó que se escriba al señor canónigo don Juan Voza, hacedor de Tenerife, haga diligencia en aquella isla por dos o tres muchachos de buena voz y que sepan leer y escribir, de diez a once años para que puedan aprender música y avise al cabildo y la forma que habrá para que vengan a esta isla..."'.

Como se ha podido observar, la procedencia de los cantores no sólo era de la isla de Gran Canaria, sino de otras como Tenerife; o el organista principal de la catedral Juan González Montañez ${ }^{8}$ que era de la isla de La Palma, por lo que la catedral se nutría de todos los rincones de las islas con el fin de obtener músicos para su capilla.

En octubre de 1681, viéndose Durón en la necesidad de tener un arpista en la catedral para la interpretación del repertorio litúrgico, especialmente para las obras policorales, le realiza una serie de pruebas a un músico procedente de la isla de Madeira, pasándolas éste satisfactoriamente. De esta manera, es contratado por un sueldo de 200 ducados y 24 fanegas de trigo. En las actas capitulares, además aparece

5 TORRE CHAMPASAUR DE TRUJILLO (1999): 830.

6 ACCLP (= Actas Capitulares de la Catedral de Las Palmas), 29.01.1677. TORRE CHAMPASAUR DE TRUJILLO (1999): 831.

7 ACCLP, 29.01.1677. TORRE CHAMPASAUR DE TRUJILLO (1999): 831.

8 ACCLP, 23.07.1678. Se cita lo siguiente: "En este cabildo, llamado ante diem para resolver si se recibirían dos muchachos para tiples que se han traído del lugar de Arucas, vistos dichos muchachos y el informe del maestro de capilla [Diego Durón], a quién se remitieron...". Esto significa que se traían niños cantores desde diferentes puntos de la isla para su inclusión en la catedral. un dato importante que no suele aparecer normalmente: las obligaciones a las que se le somete, lo que en las ACCLP (= Actas Capitulares de la Catedral de Las Palmas) se denomina como "Pandecta". Observada su importancia se adjunta su transcripción”:

1. Primeramente a de estudiar los contrapuntos y principios de composisión, y a de enseñar vno o dos muchachos, los que el cauildo le encomendase.

2. Ha de asistir el harpista al choro todas las visperas y misas de primera clase, y lo mismo en las misas de dotaciones fuera y dentro de la iglesia.

3. Las misas de segunda clase en que vbiere motete a de aconpañar y en otra qualquiera ocasión en que el maestro de capilla le auisare que ay motete.

4. En las misas de rogativas en que se cantare de choro.

5. todas las funsiones en que vbiere villansicos fuera y dentro de la yglesia asistiendo el cauildo.

6. En la Cuaresma a todas las ferias a que se cantare con música el Audiuua nos o solo por algún músico el canto llano.

7. Así mismo a de asistir a todas las completas que se cantan los sábados y las demás completas solemnes que se cantan entre año, y todos los días que vbiere motete.

8. La Semana Santa a las Lamentasiones de capilla y de vos sola al canto llano. Los misereres.

9. Las Dominicas que tubieren In exitu de música y en los officios de difuntos en que vbiere música, y quando el cauildo o maestro de capilla le ordenaren. Y [que] se pueda sentar en vn banquillo para tocar con mas comodidad.

Durante este período, el maestro de capilla se preocupa por la inclusión de instrumentistas y de su formación, de manera que se contrata a un ministril de sacabuche ${ }^{10}$ y a un ministril de corneta (Pedro Díaz Naranjo) ${ }^{11}$. A pesar de ello, una serie de músicos de la capilla de la catedral de Las Palmas de Gran Canaria estaban temporalmente en ella, dado que aprovechaban la ubicación geográfica de las islas para su marcha a "las Indias". Un ejemplo claro se puede observar

9 ACCLP, 20.10.1681. Véase, TORRE CHAMPASAUR DE TRUJILLO (2000): 381.

10 ACCLP, 18.01.1683. TORRE CHAMPASAUR DE TRUJILLO (2000): 354

11 ACCLP, 27.07.1682. TORRE CHAMPASAUR DE TRUJILLO (2000): 352 . 
en el mozo de coro Juan Martín, que es sustituido por Pedro Alexandro al dejar su puesto vacante por embarcarse para América durante este período ${ }^{12}$.

En el año 1682, Durón viaja a la isla de Tenerife con la intención de ordenarse sacerdote, teniendo a partir de este momento un cargo eclesiástico ${ }^{13}$. Posteriormente se encarga de escribir la música para el Corpus, deber obligatorio para el maestro de capilla, por lo que prepara a los mozos de coro para ello y se solicita la vestimenta adecuada para tales fechas ${ }^{14}$. Los mozos de coro, al igual que el maestro de capilla, cobran un dinero aparte por las actuaciones en estas festividades, dado que un mozo de coro cobra 30 doblas más cuatro fanegas de trigo al año, al igual que un sochantre; y por las interpretaciones fuera del culto litúrgico obligatorio, cobraban ocho reales ${ }^{15}$. Durante este período también es destacable el especial hincapié que hace Durón por el uso de la corneta en el repertorio litúrgico ${ }^{16}$, al igual que la adquisición de un nuevo instrumento para la capilla, un "tenorete" 17 .

Los mozos de coro tuvieron un papel muy destacado durante el magisterio del maestro de Brihuega, dado que les obligaba a asistir a clases de canto $^{18}$, a leer y escribir ${ }^{19}$, e incluso a tocar algún instrumento. De hecho, cuando los mozos de coro comenzaban a mudar la voz y no podían seguir trabajando como cantores para la catedral, solicitaban aprender con precisión algún instrumento, como fue el caso de los mozos de coro Francisco Valentín ${ }^{20}$, Pedro Brito ${ }^{21}$ y de Felipe Boza, del que se comenta lo siguiente ${ }^{22}$ :

"Al memorial de Phelipe Voza, mozo de coro aplicado a la capilla de música en que dice que por estar en muda

12 ACCLP, 05.10.1683. TORRE CHAMPASAUR DE TRUJILLO (2000): 354.

13 ACCLP, 09.09.1683. TORRE CHAMPASAUR DE TRUJILLO (2000): 356.

14 ACCLP, 19.06.1682. TORRE CHAMPASAUR DE TRUJILLO (2000): 352.

15 ACCLP, 12.06 .1682 y 11.03.1686. TORRE CHAMPASAUR DE TRUJILLO (2000): 352 y 365.

16 ACCLP, 21.05.1685. TORRE CHAMPASAUR DE TRUJILLO (2000): 361 .

17 ACCLP, 04.07.1685. TORRE CHAMPASAUR DE TRUJILLO (2000): 351.

18 ACCLP, 11.10.1686. TORRE CHAMPASAUR DE TRUJILLO (2000): 366.

19 ACCLP, 04.07.1698. TORRE CHAMPASAUR DE TRUJILLO (2000): 407.

20 ACCLP, 21.07.1690. TORRE CHAMPASAUR DE TRUJILLO (2000): 383.

21 ACCLP, 28.02.1692. TORRE CHAMPASAUR DE TRUJILLO (2000): 391.

22 ACCLP, 17.08.1696; 17-12-1696. TORRE CHAMPASAUR DE TRUJILLO (2000): 399. sin esperanza de voz, se aplicó a aprender bajón con licencia del cabildo...".

La formación de los mozos de coro era de gran importancia para Diego Durón, ya que de esta manera se prescindiría de tener que pedirlos a la península, siendo esto mucho más factible para la catedral porque no gastaban tanto en músicos procedentes de otras provincias, lo que suponía un gasto mucho más grande. Su preocupación era tan amplia, que a sus discípulos se los llevaba a su casa para impartirles clase de música, tal y como se demuestra en las ACCLP de enero de 1685, al referirse a su discípulo Francisco Castellanos ${ }^{23}$ :

"En este cabildo llamado ante diem para resolver sobre el memorial de Francisco Castellanos, mozo de coro, en que pide licencia para ir a aprender música en casa del maestro de capilla Diego Durón y para ello se le excusa de la asistencia del coro...".

Esto era bastante común, y se puede observar en diversas actas capitulares cómo diferentes mozos de coro piden permiso al cabildo para asistir a la casa de Durón para recibir formación musical, como es el caso también de Mathías Gutiérrez, entre otros muchos ${ }^{24}$.

Si los mozos de coro faltaban a su deber o no asistían a las clases de canto o de gramática, eran penalizados económicamente. Igualmente ocurría en función de su comportamiento durante las interpretaciones en las horas litúrgicas en la cate$\mathrm{dral}^{25}$. Un caso ejemplar es el ocurrido a Pedro Díaz Naranjo, el cual fue sancionado económicamente por maleducado ${ }^{26}$.

Gracias a las actas capitulares, sabemos que el copista que tenía hasta ese momento la catedral durante este período era Antonio de Castro, por lo que las obras atribuidas de Durón de este período, que no son autógrafas pero que sí contienen su autoría, fueron realizadas por el copista anteriormente mencionado ${ }^{27}$. A partir de este año, se nombra a otro "por su buena calidad de la letra", llamado Álvaro Durán de Estañol, que tendría la obligación de reconstruir algunos libros en mal estado de conservación ${ }^{28}$.

23 ACCLP, 22.01.1685. TORRE CHAMPASAUR DE TRUJILLO (2000): 360

24 ACCLP, 24.01.1698. TORRE CHAMPASAUR DE TRUJILLO (2000): 405.

25 ACCLP, 05.02.1685. TORRE CHAMPASAUR DE TRUJILLO (2000): 360.

26 ACCLP, 08.10.1700. TORRE CHAMPASAUR DE TRUJILLO (2000): 422.

27 ACCLP, 23.03.1683. TORRE CHAMPASAUR DE TRUJILLO (2000): 354.

28 ACCLP, $12.07 .1683 ; 09.09 .1683$ y 19.05 .1684 . TORRE CHAMPASAUR DE TRUJILLO (2000): 354. 
En el año 1685, Durón reciba la oferta de trabajar como maestro de capilla en la catedral de Osma sin realizar los exámenes que normalmente se requerían, gracias a la mediación que realizó su maestro Alonso Xuárez. Durón, al verse tentado por este nuevo puesto de trabajo decide marcharse, por lo que comunica su decisión al cabildo de la catedral. El cabildo de la catedral tras valorar la marcha de Durón accede a aumentarle el sueldo con 50 ducados más, con el fin de convencerlo para que no marche a la península, por lo que Diego Durón accede a quedarse en Canarias ${ }^{29}$.

El año 1686 parece tranquilo, dado que sólo se detallan préstamos que da el cabildo de la catedral a algunos músicos sin especificar la razón; y dos aspectos más, uno es una paga extra que reciben los mozos de coro por cantar las Pasiones en Semana Santa ${ }^{30}$, y el siguiente, es el interés que sigue teniendo Durón por la formación de los mozos de coro, a los cuales vuelve a llamar la atención por su asistencia poco regular a la escuela de canto ${ }^{31}$.

Posteriormente se debe destacar la llegada de cuerdas para el arpa procedentes de Roma ${ }^{32}$, las cuales eran pedidas siempre a través de Sevilla, al igual que los cantores, dado que la catedral de Las Palmas de Gran Canaria dependía de ésta. Un aspecto observado bastante curioso, es que el gasto de las cuerdas del instrumento (a pesar de lo caras que eran), siempre corría a cargo del músico y no del cabildo de la catedral; pero si un instrumento era dañado por algún músico, entonces era el cabildo quien pagaba el arreglo ${ }^{33}$.

En todo este período, siempre se notifica en el mes de septiembre un permiso que se les da a los músicos de entre 15 y 30 días para realizar la vendimia en ese mes; Este permiso incluye igualmente al maestro de capilla, Diego Durón ${ }^{34}$.

En 1689 se nombra organista mayor de la catedral de Las Palmas de Gran Canaria a Juan González Montañéz ${ }^{35}$. Posteriormente se le darían las obligaciones que tendría al sustentar dicho puesto, ya que existían en ese momento tres órganos en la catedral ${ }^{36}$.

En 1690 el cabildo de la catedral nombra como mayordomo de la iglesia de los Remedios al maestro de capilla Die-

29 ACCLP, 21.05.1685. TORRE CHAMPASAUR DE TRUJILLO (2000): 360 .

30 ACCLP, 11.03.1686. TORRE CHAMPASAUR DE TRUJILLO (2000): 366.

31 ACCLP, 11.10.1686. TORRE CHAMPASAUR DE TRUJILLO (2000): 366.

32 ACCLP, 29.03.1688; 7-02-1702; 20-10-1702; 11-08-1703. 33 ACCLP, 28.07.1687. TORRE CHAMPASAUR DE TRUJILLO (2000): 369.

34 ACCLP, 15.10.1687.

35 ACCLP, 04.09.1689.

36 ACCLP, 27.10.1690. go Durón ${ }^{37}$, pero al parecer no fue de su agrado tal nombramiento dado que al poco, seis días más tarde, se nombra como mayordomo de esa iglesia al canónigo Joseph de Loreto ${ }^{38}$.

En la década de 1690 se observa un cambio en la catedral debido a un mayor incremento del uso de instrumentistas en la capilla de música, y de algunos cantores (incluso extranjeros), bajo el mandato de Diego Durón. Se traduce en las actas capitulares, dado que el maestro de capilla pide más chirimías para sus interpretaciones ${ }^{39}$, entran músicos nuevos como ayudas del arpista y bajón ${ }^{40}$, y nuevos músicos (antes cantantes) entran a aprender instrumentos tras la muda de voz, como ocurre en los siguientes casos:

- Francisco Valentín pide permiso a la catedral para aprender a tocar el bajón ${ }^{41}$.

- Pedro de Brito pide permiso a la catedral para aprender a tocar el bajón ${ }^{42}$.

- Phelipe Pérez entra como arpista de la catedral ${ }^{43}$.

- Llegada de dos mozos de coro nuevos procedentes de Tenerife ${ }^{44}$.

- Phelipe Santiago de Boza entra como bajón de la catedral $^{45}$.

- Manuel Farías muda la voz y aprende a tocar la corneta $^{46}$.

- Se contrata a un portugués como mozo de coro $^{47}$.

- Se contrata a otro organista, Juan Álvarez de Castro, recomendado por el hermano de Diego Durón, Sebastián Durón procedente de Madrid ${ }^{48}$.

Probablemente existan muchas más noticias referentes a este aspecto, pero lamentablemente, el libro que contiene las actas capitulares entre 1692 y 1695 está en deplorable estado, por lo que no se ha podido extraer información alguna.

El mal estado de los manuscritos en este período, queda patente ya que consta un acta capitular en donde se especifica la preocupación en este sentido y sobre la compra de papel de calidad ${ }^{49}$. Por ello probablemente se paga una alta cantidad de dinero al copista de la catedral, por copiar los 
villancicos de Diego Durón (no se especifica ni la cantidad, ni los que son ${ }^{50}$. Incluso se manda encuadernar el libro de coro para su mejor conservación ${ }^{51}$.

La década de 1690 finaliza sin grandes cambios, sólo se señala la ausencia de Durón por enfermedad ${ }^{52}$, el robo de un capitulario del $\operatorname{coro}^{53}$ y la amonestación a un ministril por mala educación, el cual es sancionado económicamente ${ }^{54}$. Otros serían automáticamente despedidos por su mal comportamiento y "por ser de malicia", como fue el caso del mozo de coro Pedro de Brito ${ }^{55}$. El mismo cabildo se encargaba muchas veces de llamar al orden a las personas que tenía bajo su mandato, como en el caso del librero Juan Guerra. Éste fue llamado al orden por desobediencia, siendo castigado físicamente con 4 golpes con una vara en cada mano. El acta capitular lo especifica de la siguiente manera ${ }^{56}$ :

"da cuenta al cabildo de la inobediencia de Juan Guerra, librero; conferido y votado se acordó por la mayor parte que el presente secretario reprenda a dicho Juan Guerra y en su presencia le dé el maestro ocho palmetas, cuatro en cada mano, y de resistirse se dé por despedido".

Los problemas con el estado de conservación de los manuscritos siguen dando problemas. Durón pide al cabildo la restauración de otros tantos manuscritos; incluso se cita lo siguiente ${ }^{57}$ :

"con informe del maestro de capilla Diego Durón sobre el memorial de la capilla de ministriles de esta santa iglesia, en que dice que el libro de canciones además de ser muy antiguo está tan hecho pedazos que no pueden usar de él...".

Además de la suculenta entrada de músicos y cantantes como mozos de coro a la catedral durante este período ${ }^{58}$, también debemos señalar que varios se marcharon a las Indias como fue el caso de los mozos de coro Gregorio Rivero ${ }^{59}$, Luis Lorenzo $^{60}$, Gerónimo Pérez ${ }^{61}$ y Mathías Gutiérrez ${ }^{62}$.

50 ACCLP, 21.01.1698

51 ACCLP, 01.08.1698.

52 ACCLP, 03.10.1698.

53 ACCLP, 21.04.1698.

54 ACCLP, 08.10.1700.

55 ACCLP, 05.11.1706.

56 ACCLP, 05.11.1708.

57 ACCLP, 18.04.1701

58 ACCLP, 24.11.1702.

59 ACCLP, 19.08.1701.

60 ACCLP, 09.06.1702.

61 ACCLP, 08.08.1707.

62 ACCLP, 23.11.1707.
A pesar de ello, diversos mozos de coro, al cambiarles la voz o "estar en proceso de muda" aprovechaban la ocasión para formarse como instrumentistas en la catedral ${ }^{63}$, aunque otros eran automáticamente despedidos ${ }^{64}$.

En el año 1702, Diego Durón cobra 70 reales por la composición de 9 obras, aunque realmente no se señala qué obras son ${ }^{65}$.

En 1703 se observa un dato importantísimo que data de la compra de libros de música por parte del cabildo de la catedral. En él se detalla la adquisición de un libro de música compuesto por José de Torres, organista de la Real Capilla de Madrid, el cual componía una gran cantidad de obras policorales. El documento señala lo siguiente ${ }^{66}$ :

“...si se comprara un libro de facistol con ocho misas en música, con un motete y el Asperges que dio a la estampa don Joseph de Torres , organista de la Real Capilla de su Magestad, conferido y votado... que compre el libro que refiere a don Joseph de Torres...".

Éste es un dato importante, ya que a la hora de analizar las obras de Durón se podrá observar realmente si su estilo está más próximo a lo que se realizaba en la península, o si realmente desarrolló un estilo personal.

En los últimos meses de 1703, el cabildo de la catedral realiza una rebaja en los salarios de los clérigos y músicos, en la que también entraba el maestro de capilla Diego Durón. Al final acuerdan mantenerle el sueldo sin realizar rebaja alguna, por lo que se le conserva un salario de 300 ducados y 24 fanegas de trigo ${ }^{67}$.

Los organistas Juan González Montañés y Fernando Carvajal de Guanarteme, comenzaron a formar discípulos. En el año 1703 muere el segundo organista, Fernando Carvajal de Guanarteme ${ }^{68}$, por lo que entra en su lugar su alumno, antiguo mozo de coro y luego ministril Felipe Bosa Lizaga.

Un mes más tarde también moriría el arpista de la catedral, Felipe de Armas, por lo que entra en su lugar su discípulo Francisco Antonio Losada ${ }^{69}$. Tras la muerte de algún músico de la catedral, se observa frecuentemente cómo el cabildo tiene que ayudar a sus familias, dado que una vez muerto el cabeza y sustento de familia, ésta quedaba sin medio alguno, por lo que la catedral tenía que hacerse cargo durante una temporada de estas familias hasta que salieran

63 ACCLP, 08.07.1701.

64 ACCLP, 09.03.1702.

65 ACCLP, 28.09.1702.

66 ACCLP, 31.08.1703.

67 ACCLP, 28.09.1703.

68 ACCLP, 10.12 .1703$.

69 ACCLP, 25.01.1704. 
adelante. Un ejemplo claro se observa en las continuas ayudas que recibió la familia del antiguo arpista de la catedral, Felipe Armas ${ }^{70}$.

A mediados de 1704, la capilla de música se queda durante una temporada sin organista, sin especificar por qué, por lo que se le pide a los instrumentistas que suplan con música instrumental las partes del órgano. Si no se hacía así, serían penalizados con dos reales ${ }^{71}$.

A finales del mismo año, la plaza de arpista queda vacante, y es ocupada por Francisco Antonio Quiroga, con un salario de 100 ducados y un cahíz de trigo, pero con una condición, "con calidad y condición que se ha de reformar el pelo y mangas, como ministro de esta santa iglesia"72.

En 1705 Diego Durón recibe 100 reales, la cifra acordada con anterioridad, por la composición de los villancicos de Kalenda, Nochebuena y Reyes ${ }^{73}$, cantidad que muchas veces tiene que recordarle al cabildo para que se le pague ${ }^{74}$.

Además de los instrumentos normalmente utilizados en la capilla y que con anterioridad he señalado, como bajones, corneta, chirimías, sacabuches, flautas y órgano, el maestro de capilla ordena la compra de un violón ${ }^{75}$, que sería después tocado por Fernando Ferreira ${ }^{76}$, aunque después se lo darían a Eugenio Zumbado por mostrar mejor predisposición ${ }^{77}$.

Al estar cada vez más viejo el organista principal de la catedral, Juan González Montañez, se manda traer uno de la península, el cual llegaría procedente de Sevilla. Se trata de Juan Blanco, natural de Ávila, que tras ser examinado por el teclista de la Capilla Real, Diego Jaraba y Bruna, llegó a la isla en julio de $1710^{78}$. Para suplir a Montañez (el antiguo organista), el cabildo de la catedral quería con empeño a un individuo de la península competente, aunque el maestro de capilla Diego Durón insistía en contratar al isleño Sebastián Henríquez. El cabildo exigía la llegada de un organista con "alguna inteligencia de componer y repentizar"79. Finalmente, Juan Blanco es el organista contratado por el cabildo de la catedral de Las Palmas de Gran Canaria, dándole posesión de los órganos y los clavicordios ${ }^{80}$. Los conocimientos sobre órganos del nuevo organista son muy importantes dado que

70 ACCLP, 29.01.1704; 01.02.1704.

71 ACCLP, 11.07.1704.

72 ACCLP, 03.11.1704 y 10.11.1704.

73 ACCLP, 16.01.1705.

74 ACCLP, 23.11.1707; 15.01.1709; 13.01.1710.

75 ACCLP, 20.12.1709.

76 ACCLP, 21.10.1710.

77 ACCLP, 22.08.1710.

78 ACCLP, 04.07.1710.

79 ACCLP, 10.05.1709

80 ACCLP, 15.07.1710. también realiza la función de ponerlos a punto y arreglar$\operatorname{los}{ }^{81}$

Un mes más tarde de la llegada del nuevo organista, Diego Durón le envía a uno de los discípulos mas aventajados, Miguel Ramos, para que "le enseñe con el cuidado que se espera de su puntualidad". ${ }^{82}$ De la misma manera el maestro de capilla está interesado en enseñar a tocar el violón a otro discípulo relevante como es Eugenio Zumbado, puesto que hacía falta para la interpretación en el culto litúrgico ${ }^{83}$.

Fuera del contexto de la catedral y su capilla, hay que mencionar la ayuda que solicita al cabildo de la catedral para que se le pague "enteramente el tercio de Navidad" dado que debe pagar un esclavo que ha comprado ${ }^{84}$.

El tímido interés de Durón por los nuevos derroteros se refleja en sus composiciones tardías, entre las que aparece alguna cantata y un estilo un tanto más suelto. Por esta razón, el cuatro de diciembre de 1719 su antiguo discípulo Alonso Román, al despedirse de la catedral por tuberculosis, alega que "las músicas cada vez están más vivas y violentas, que muchas veces no las puede percibir con su velocidad el oído" ${ }^{85}$.

Un aspecto a destacar en este período final del compositor Diego Durón es el interés por aumentar el número de instrumentos en las funciones litúrgicas, por lo que lo amplía con la compra de un clarín y un oboe para la capilla ${ }^{86}$.

En los diez últimos años de vida de Diego Durón, la capilla de la catedral se vio notablemente afectada por la crisis económica que sufría la isla debido a la sequía. A ello también hubo que añadirle la invasión de moneda falsa que afectó a la economía isleña. En estos diez últimos años, el maestro de capilla apenas aparece en las actas capitulares de la catedral, excepto en momentos puntuales. Lo que sí se observa es que las actas catedralicias se reducen mayoritariamente a peticiones de los músicos y demás personal de la iglesia para que se les concedan préstamos sobre sus atrasos. Debido a estas penurias económicas, hubo músicos que abandonaron la capilla de la catedral para embarcarse para las Indias, como fue el caso de Francisco Castrillo ${ }^{87}$.

El organista peninsular Juan Blanco contraería una serie de enfermedades que lo tendrían prácticamente apartado de sus funciones ${ }^{88}$.

81 ACCLP, 09.05.1713.

82 ACCLP, 22.08.1710.

83 ACCLP, 20.12.1710

84 ACCLP, 19.12.1713.

85 ACCLP, 04.12.1719.

86 ACCLP, 22.01.1720

87 ACCLP, 20.12.1723. TORRE CHAMPASAUR DE TRUJILLO (2002): 357.

88 ACCLP, 09.05.1721. TORRE CHAMPASAUR DE TRUJILLO (2002): 340. 
En octubre de 1730 Diego Durón se siente ya con pocas fuerzas para seguir componiendo, debido a los continuos achaques que presenta, por lo que le pide al cabildo de la catedral que le libere de componer y que se aproveche para ello toda la composición realizada durante su magisterio desde $1676^{89}$.

El 5 de abril de 1731 muere el maestro de capilla Diego Durón, nombrando como maestro interino a su discípulo Diego Hernández de la Cámara, hasta que posteriormente llegara Joaquín García ${ }^{90}$.

\section{MANUSCRITOS DE DIEGO DURÓN EN LA CATEDRAL DE LAS PALMAS DE GRAN CANARIA}

En el archivo de la catedral de Las Palmas de Gran Canaria se encuentran todas las obras del maestro de capi1la Diego Durón, no conservándose ninguna en ningún otro archivo de España. Esto se debe a que Durón permaneció como maestro de capilla de la catedral desde 1676 hasta 1730, es decir, 54 años.

Del maestro se conservan una gran cantidad de obras tanto en latín como en romance, siendo en su gran mayoría villancicos. En total contabilizamos 420 obras en romance (todas ellas villancicos), y 47 obras en latín. Pero, ¿a qué se debe tanta diferencia en cuanto a la cantidad de música con texto en latín frente a las composiciones en lengua vernácula?

Esa gran diferencia entre las obras de Durón no es extraño, dado que el uso que se hacía del villancico en España era mucho mayor. El villancico -como composición religiosa en romance- contaba además, frente a los responsorios, con varias ventajas, que le permitieron abrirse paso con un gran y duradero éxito: no estaba sujeto al rito, lo que le proporcionaba una cierta autonomía de funcionamiento; poseía un mayor grado de libertad, al servirse de la lengua vernácula, alejada de la servidumbre oficialista del latín; y por último, gozaba de un cierto carácter suntuario, en virtud del cual apareció y se desarrolló sobre todo en las festividades De tempore (Navidad, Corpus) y De sanctis (sobre todo fiestas de la Virgen), de fuerte raigambre popular. Así, el villancico llegó a ocupar en España otros lugares en el marco de la liturgia. Por ejemplo, sustituía al gradual o al ofertorio cuando se cantaba un villancico "de calenda" (que anuncia las fiestas del día siguiente), o villancicos concretos para las

89 ACCLP, 30.10.1730. TORRE CHAMPASAUR DE TRUJILLO (2002): 408.

90 ACCLP, 05.04.1731. TORRE CHAMPASAUR DE TRUJILLO (2002): 409. vísperas de Navidad, procesión del Corpus Christi, octava del Corpus, fiestas de la virgen y de los santos, o la procesión del día de Reyes, entre otras cosas ${ }^{91}$.

Si observamos el número de obras compuestas por otros autores del siglo XVII español, como Juan de Navas, Carlos Patiño, Matías Navarro, Urbán de Vargas, maestro Capitán, Juan Pérez Roldán y otros muchos, la diferencia cuantitativa entre la música litúrgica y la no-litúrgica es similar.

De la producción en latín de Diego Durón, tan sólo ocho obras están fechadas por el mismo autor, frente al resto, que están sin fechar. En cambio, su producción en romance está mayoritariamente fechada. Ahora bien, todas las obras están fechadas entre 1676, año en que ingresa como maestro de capilla en la catedral de Gran Canaria y 1730, dado que un año después, en 1731, fallece.

El catálogo que se ha realizado acerca del archivo de la catedral de Las Palmas, es el publicado por Lola de la Torre en los años 1964 y 1965 ${ }^{92}$. En él se han recogido y catalogado todas las obras que en la catedral se encuentran, incluyendo igualmente las obras de Diego Durón. A pesar de ello, existen documentos que indican otros inventarios realizados entre los siglos XVII y XVIII, que señalan las obras existentes en ese momento. Éste es el caso del catálogo realizado por Baltasar Zambrana, ya desaparecido.

A continuación se detalla la producción en latín de Diego Durón, clasificada por géneros litúrgicos, dado que en el catálogo realizado por Lola de la Torre aparecen todas diseminadas ${ }^{93}$. El agrupamiento de las obras es el siguiente:

\section{- Salmos:}

- Miserere de Eccos. B/IV-2.

- Beatus vir, a 11 v. B/VII-8.

\section{- Cánticos:}

- Nunc Dimittis, a 7 v. B/V-5.

- Nunc Dimittis, a 7 v. B/V-6.

- Lamentaciones:

- Lamentación $1^{\mathrm{a}}$ del Miércoles Santo, a 11 v. B/VI-2.

- Lamentación del Jueves Santo, a 9 v. B/VI-3.

- Lamentación del Viernes Santo, a 6 v. B/VI-4.

- Himno:

- Gloria, laus et honor, B/V-3.

91 POPE (1944): 15-27. EZQUERRO ESTEBAN (1998): 17. 92 TORRE CHAMPASAUR DE TRUJILLO (1964): 181-242. TORRE CHAMPASAUR DE TRUJILLO (1965): 147-203. 93 TORRE CHAMPASAUR DE TRUJILLO (1964): 192. 
- Gradual:

- Laetatus sum, a 11. B/V-14. Laetatus sum, a 7. (1679). B/V-2.

- Misas:

- Missa, Ad Libitum, a 8 v. B/VIII-1.

- Missa, Surge, Prorpera, Amica Mea, a 7 v. B/VIII-2.

- Misa, a 12 v. B/VIII-3.

\section{- Magnificats:}

- Magnificat, a 7 v. B/VII-1.

- Magnificat, a 4 v. B/IX (añadido a la obra de Manuel de Tavares)

\section{- Antífonas:}

- Salve, a 8 v. B/IV-1.

- Salve, a 10 v. B/VII-10.

- Ecce sacerdos magnus, a 8 v. B/VII-13.

- Veni sancte spíritus, a 10 v. B/VII-11.

- Isti sunt, a $8 \mathrm{v}$. B/VII-12.

- Euge serve bone, B/VII-9.

- Veni sponsa christi, a 8 v. B/VII- 4.

- O sacrum convivium, a 8 v. B/V-11.

- Hodie, Simon Petrus, a 8 v. B/V-10.

- O sacrum convivium, a 8 v. B/V-11.

- Beati eritis

- Hodie, Simon Petrus

- Vulnerasti cor meum

\section{- Ofertorio:}

- Domine Jesu Christe, a 4 v. B/VII-3.

\section{- Tracto:}

- Beatus vir. B/VII-8.

\section{- Responsorio:}

- Emendemus, a 4 v. B/VII-7.

\section{- Villancicos:}

A. Villancicos de Navidad: 180.

B. Villancicos de Reyes: 57.

C. Villancicos del Corpus: 116 .

D. Villancicos de la Ascensión: 26.

E. Villancicos de Santa Ana: 12

F. Villancicos de la Asunción: 11

G. Villancicos profanos (sin ningún carácter religioso): 18

Es muy importante señalar que existen una serie de obras de diversos compositores a los que Durón añadió música y viceversa, es decir, composiciones de Diego Durón a las que otros compositores añadieron música. Los manuscritos donde Durón añadió música son los siguientes:

- B/IX. MAGNIFICAT, a 4 v., en los ocho tonos:

Obra compuesta por el compositor portugués Manuel de Tavares, la cual contiene añadidos de los compositores Nicolás Tavares (hijo de Manuel Tavares), y de Jerónimo Pérez Baylón.

\section{- B/XI-1:}

Este manuscrito, escrito con diversas tintas, diferencia a los compositores que lo han modificado y han añadido música. La mayor parte corresponde a Melchor Cabello aunque se señala en cada parte el añadido de cada compositor. En el libro se detalla lo siguiente:

- Fol. 1v.- Oficio de Quaresma, a 6 v., del $\mathrm{M}^{\circ}$. Tavares.

- Fol. 6v.- In Exitu Israel de Aegipto, a 4v. del $\mathrm{M}^{\circ}$. Tavares.

- Fol. 13v.- Pasión según San Mateo, a 4 v. del Mํ. Melchor Cabello con añadido de Diego Durón.

- Fol. 24v.- Pasión según San Marcos, a 4 v. del Mº Melchor Cabello con añadido de Diego Durón.

- Fol. 33v.- Pasión según San Lucas, a 4 v. del Mº Melchor Cabello con añadido de Diego Durón.

- Fol. 44v.- Pasión según San Juan, a 4 v. del Mº. Melchor Cabello con añadido de Diego Durón.

\section{- B/XI-2:}

Este manuscrito es una copia del manuscrito anteriormente señalado (B/XI-1), consta de 65 páginas y fue realizado por Francisco González Marina en 1808. El manuscrito presenta el mismo contenido sin ningún añadido a posteriori del anterior.

\section{Diferencias entre originales y copias}

Dentro del corpus de obras que estudiamos del compositor Diego Durón, una gran parte son autógrafas, pero otra pequeña procede de copias posteriores, fechándose la gran mayoría en el último cuarto del siglo XVIII, y una de ellas en el siglo XIX. Dentro del corpus de obras que se estudian en esta investigación, hay que señalar las que son manuscritos autógrafos o copias realizadas por el copista de la catedral, o copias realizadas posteriormente.

+Ecce sacerdos magnum. Copiose en este año de 1792.

+ $O$ altitudo Divitiarum. Año de 1682. Copiose en este año 1814. 
+ Anima mea Dominum. Posiblemente copia. Falta primera página.

+ Villancico de Kalenda a 16. Año 1692. Copia de Bernardino Valle Chinestra.

+ Lamentación del Viernes Santo a 6. Copiose de nuevo el año de 1793.

+ A tollite portas. Presenta otra caligrafía. No dice que está copiado posteriormente.

\section{Estado de conservación}

Los manuscritos en la actualidad no presentan un buen estado de conservación ya que muchos de ellos se han deteriorado a causa de las polillas, llegando a faltar algunas partes de ciertas páginas de algunos manuscritos. Igualmente las condiciones de humedad que presentan y su actual ubicación, deteriora su estado de conservación a posteriori. Las obras que en la actualidad presentan un gran deterioro y requieren una restauración urgente son:

- Lamentación del Jueves Santo a 9, 1685. B/VI-3.

- Nunc dimittis servum tuum a 7. (B/V-6).

\section{Las obras objeto de estudio}

Las obras que se han transcrito y estudiado en esta investigación han sido elegidas en función de dos premisas. En primer lugar, por el número de voces y coros que presentan $\mathrm{y}$, en segundo lugar, por el género al que pertenecen.

Por ello, he elegido obras a a seis, siete, y ocho voces divididas en dos coros. Igualmente, a diez voces en tres coros, y a catorce y dieciséis voces divididas en cuatro coros. En esta división, se puede observar tanto cómo un coro está escrito sólo para instrumentos, cómo para voces y, a su vez, qué tratamiento formal, estilístico y armónico presenta.

La elección ha sido realizada con base en criterios del género (Gattung) de las obras. Se han utilizado salmos, cánticos, antífonas, lamentaciones, magnificats y villancicos, con el fin de dilucidar cuál es el tratamiento compositivo que Durón ha establecido para cada género. Por ello, las obras seleccionadas para ser transcritas y analizadas son las siguientes:

\section{Salmos:}

- Miserere de Eccos. B/IV-2.

\section{Cántico:}

- Nunc Dimittis servum tuum, a 7. (B/V-6).

\section{Lamentaciones:}

- Lamentación del Jueves Santo, a 9, 1685. (B/ VI-3).

\section{Antífonas:}

- Ecce Sacerdos Magnus, a 8. (B/VII-13).

- Salve, a 10.

- Isti sunt, a 8 v. B/VII-12.

\section{Villancico:}

- Villancico de Kalenda a 16.

\section{Comunión:}

- Laudate Dominum omnes gentes.

\subsection{Marcas de agua}

El estudio del papel desde el punto de vista rastrológico, de las marcas de agua y de su elaboración, ha aportado a esta investigación importantes datos que desvelan aproximadamente la fecha de diversos manuscritos.

El estudio de la filigrana puede aportar elementos de crítica de inestimable valor para determinar la fecha "post quem" de un documento no datado o la autenticidad del mismo. En este sentido, el tipo de papel empleado, el formato utilizado (francés o italiano) y la forma de trazar las cinco líneas del pentagrama (rastrum) han ayudado a clasificar los manuscritos, lo que, junto al análisis estilístico de las obras, ha dejado bastante clara la periodización de sus obras.

Hasta el momento no se han descubierto datos en Canarias sobre la existencia de un molino papelero en el siglo XVII, ni en el primer cuarto del siglo XVIII, por lo que no es extraño encontrar resmas y pliegos de procedencia francesa e italiana traída por los mercaderes.

El papel con el que se realizaban las actas capitulares en la catedral de Las Palmas era de una calidad un tanto diferente al de los manuscritos con composiciones musicales. Es más, para las voces, se solía emplear un tipo de papel diferente que contrastaba con el papel empleado para las voces del órgano y acompañamiento, siendo este último mucho más oscuro y con una textura bastante más gruesa.

El estudio del papel ayuda al investigador a obtener una serie de datos sobre el soporte y su fabricación; su procedencia; análisis de las zonas de difusión y áreas de influencia de determinados molinos papeleros o fábricas, averiguando sus rutas comerciales; apoyar la datación de textos (documentales y literarios), cuya cronología no esté clara o sea dudosa.

\subsubsection{El papel en las obras de Diego Durón}

El tipo de corte empleado en las obras policorales litúrgicas de Diego Durón de Ortega es el denominado corte 
francés que era el que se utilizaba para la música en latín, frente al corte italiano que se empleaba para la música escrita en romance. La consulta de los manuscritos en el archivo de la catedral ha podido certificar las dos variantes de cortes de las planchas, que también se empleaban en las catedrales de la península ibérica, como es el caso de la catedral de Zaragoza $^{94}$ o de la catedral de Orihuela ${ }^{95}$.

El tipo de corte que normalmente se emplaba en las planchas para la música en latín era el que a continuación se expone. ${ }^{96}$

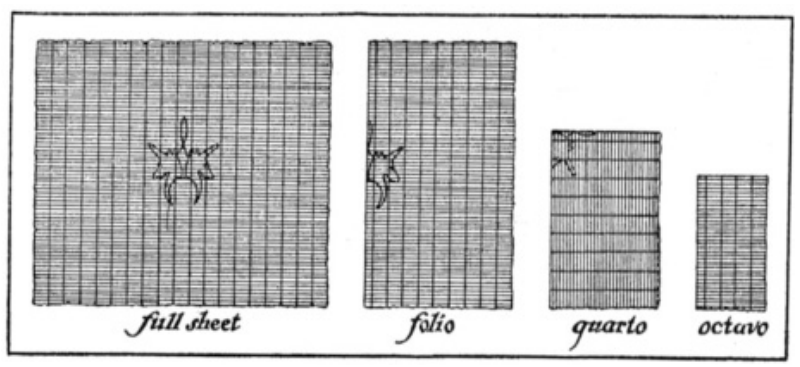

En cambio, el corte empleado para las obras en romance era diferente, cuyo ejemplo se observa a continuación:

1 .

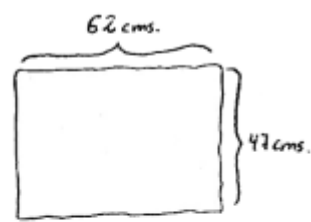

3.

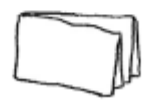

2.
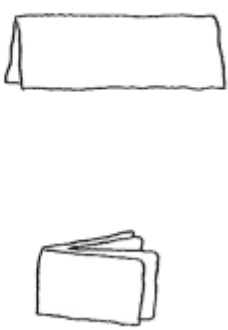

\subsubsection{Tinta empleada en los manuscritos autógrafos de Diego Durón}

Diego Durón solía utilizar, además de la tinta negra, la tinta verde y la roja. Las publicaciones de diversos especialistas sobre el tema aclara que la obtención de la tinta negra ${ }^{97}$ (mediante agallas y vitriolo) o la tinta roja ${ }^{98}$ (mediante el empleo del azafrán), era relativamente fácil de elaborar. Pero en lo que se refiere a la obtención de la tinta verde,su elaboración no era muy sencilla. Su fabricación, según Antonio Mut Calafell, tenía su complicación, no por la obtención del color, sino por su permanencia en el manuscrito, por lo que el aglutinante (agua de goma), que debía poseer, era de suma importancia. En el último cuarto del siglo XVII se publicó un interesante libro realizado por Diego Bueno en 1680 en Zaragoza, que describe el método de conseguir tinta verde:

\footnotetext{
"Secreto para hacer tinta verde: Tome media onza de cardanillo y héchelo en una escudilla bidriada con un poco de vinagre blanco y dos ebras de azafrán. Y después, cuando se ha de escribir, se rebuelve con el pincel. También se haze con verde vexiga" ${ }^{\prime 9}$.
}

Otros autores como Juan de Icíar conseguían el color verde mediante las flores de lirio. Icíar lo explicaba de la siguiente manera en 1548:

"Y, hecho esto, toman unos paños de lino, que sean una mano poco más o menos de ancho cada uno, y mójanlos en aquella agua dos o tres veces, y pónenlos a secar. Y después de secos, toman un barreñón de urinas viejas y toman unos palitos y pónenlos encima dellos, de suerte que no lleguen a mojarse con las urinas, sinó que sólo les dé el hedor de las urinas, y con esto queda hecho"100.

Posiblemente fuera alguno de estos procedimientos mediante el que se realizara la tinta verde empleada por Diego Durón en sus obras. Ello implica lo cuidadoso que era a la hora de realizar sus composiciones, dado que el empleo de diversas tintas en los manuscritos musicales, no era muy común en la penísula ibérica.

A continuación se puede ver un extracto de uno de los manuscritos donde Diego Durón emplea diversos tipos de tinta:

97 ZERDOUN BAT-YEHOUDA (1983): 17 y 353.

98 MUT CALAFEL (2003): 473-475.

99 BUENO (1690): 27. Recogido por MUT Y CALAFELL (2003): 585-596.

100 ICÍAR (1548): 20-21. 


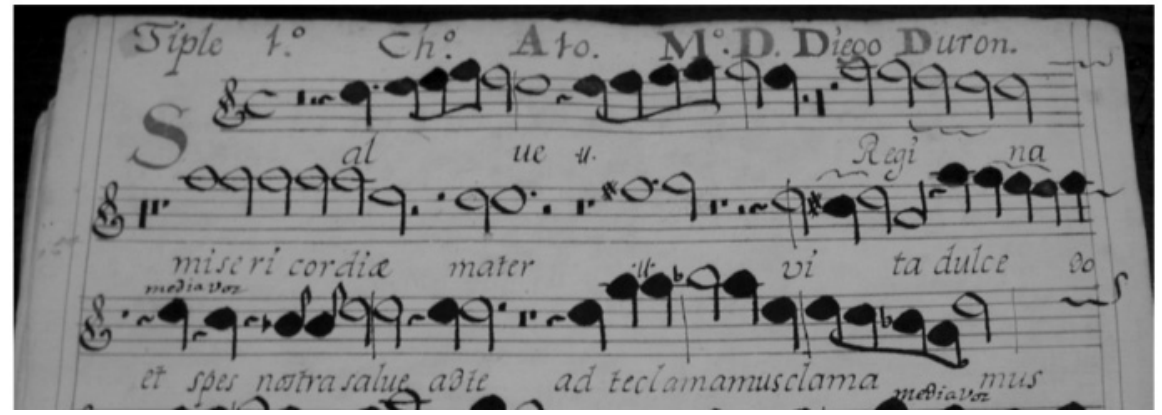

\subsubsection{Calidad del papel y estudio de los corondeles}

La catedral de Las Palmas de Gran Canaria adquiría habitualmente las resmas de papel necesarias para su administración. Los molinos papeleros vendían normalmente el papel por resmas, lo que equivale a: 1 resma $=20$ manos $=$ 500 pliegos. El papel comprado por la catedral se distribuía según sus necesidades capitulares: archivo general, secretaría, juntas de fábrica, "quinque libris", gastos, administración de sacristía y, cómo no, la capilla de música.

El análisis realizado de los manuscritos tras la muestra recogida en la catedral de Las Palmas certifica que en su mayoría están compuestos aproximadamente en un $90 \%$ de lino y un $10 \%$ de algodón, además de algunas fibras de ramio en proporción mínima. Las proporciones de lino y de algodón varían entre los manuscritos, observando en ocasiones una proporción de un $30 \%$ de algodón y $70 \%$ de lino.

La calidad del papel empleado en la catedral de Las Palmas de Gran Canaria era muy variada, dado que llegaba de diversas partes de Europa. Esto implicaba que su calidad no era homogénea sino bastante heterogénea. Por esa razón, el color del papel de los manuscritos es muy variado. Unos son mucho más claros que otros, cuya causa era el tipo de agua empleada en primer lugar y en segundo lugar, el material con el que está hecho. Para la fabricación del mismo se empleaban tejidos usados, como trapos e hilos o algunos vegetales, como cáñamo, lino o madera descortezada.

Un ejemplo de planchas oscuras en la obra de Durón se puede observar en el siguiente ejemplo:

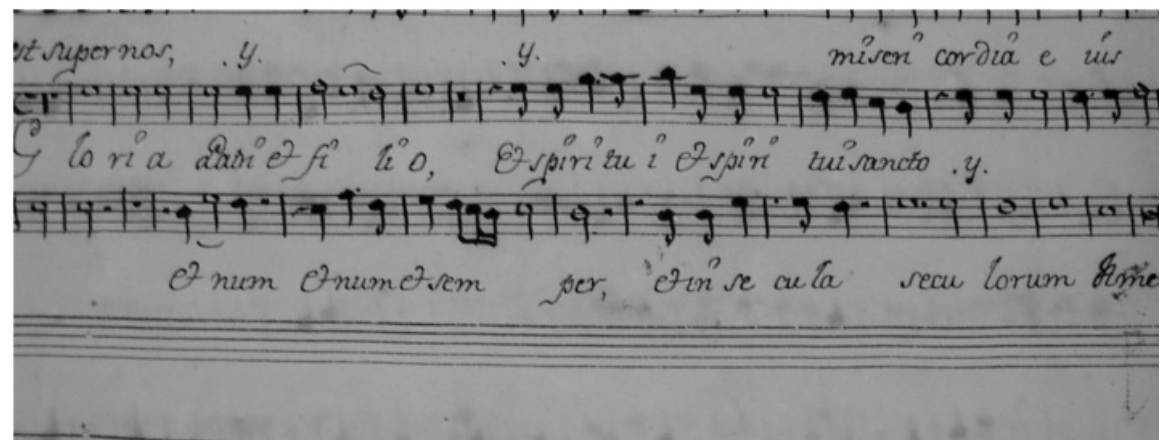

Por otro lado, también se emplean planchas de papel mucho más claras en los manuscritos de Durón, como se puede observar en el ejemplo:

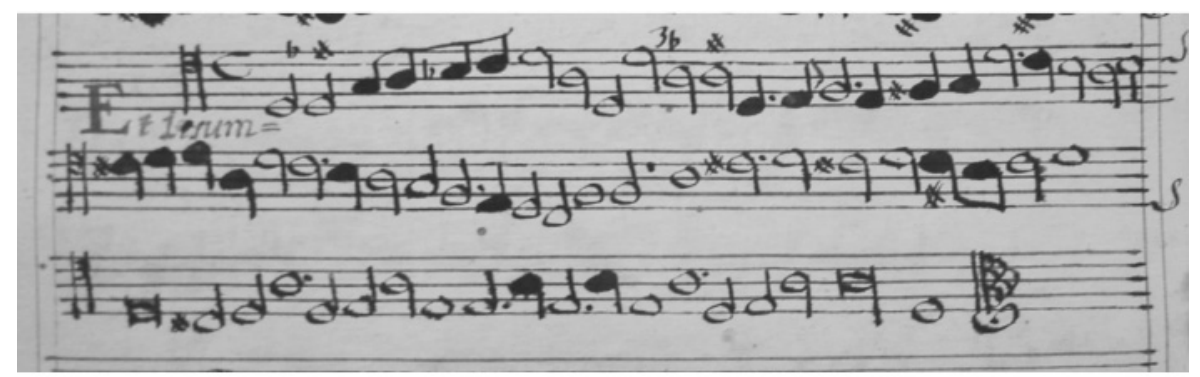


La calidad del papel estaba en función de múltiples factores, como su dureza, rigidez y grosor. La facilidad o resistencia a la rotura era un factor determinante de su calidad, la cual estaba íntimamente ligada al proceso de fabricación y secundariamente condicionado por las materias primas con que se fabricó. De hecho, el papel, en la Edad Media, al poseer una técnica mucha menos desarrollada, solía ser grueso e incluso esponjoso, por lo que se apreciaban las fibras largas originales. Con el tiempo, las fibras se hicieron mucho más cortas, debido a la mejor preparación de la pasta; el papel se hizo mucho más delgado, perdió porosidad y finalmente presentaba un mejor acabado, como se observa en las planchas de papel del siglo XVII.

La forma en la que se colocaban los corondeles a la hora de fabricar el papel, aclara muchos datos sobre la calidad del mismo. Sobre la trama que forman los corondeles y los puntizones se destaca la filigrana y éstos pueden contribuir a la datación de los documentos. Cuando la pasta del papel se trabaja poco y mal, las fibras son largas y gruesas, y por lo tanto, la criba formada por los corondeles y los puntizones presenta una mala factura.

Cuanto más regular sea la distancia entre los corondeles (hilos separados puestos en la dirección vertical del pliego) mejor calidad tendrá el papel. A este respecto, la metodología de Monique Zerdoun es probablemente la más actualizada en este tema ${ }^{101}$. Siguiendo su metodología se han medido los corondeles de los manuscritos autógrafos de Diego Durón de Ortega.

En el ejemplo que a acontinuación se expone se han medido los corondeles del manuscrito autógrafo Salve a 10 con la signatura B/VII-10. Las cifras que se han colocado en el margen inferior están medidas en centímetros.

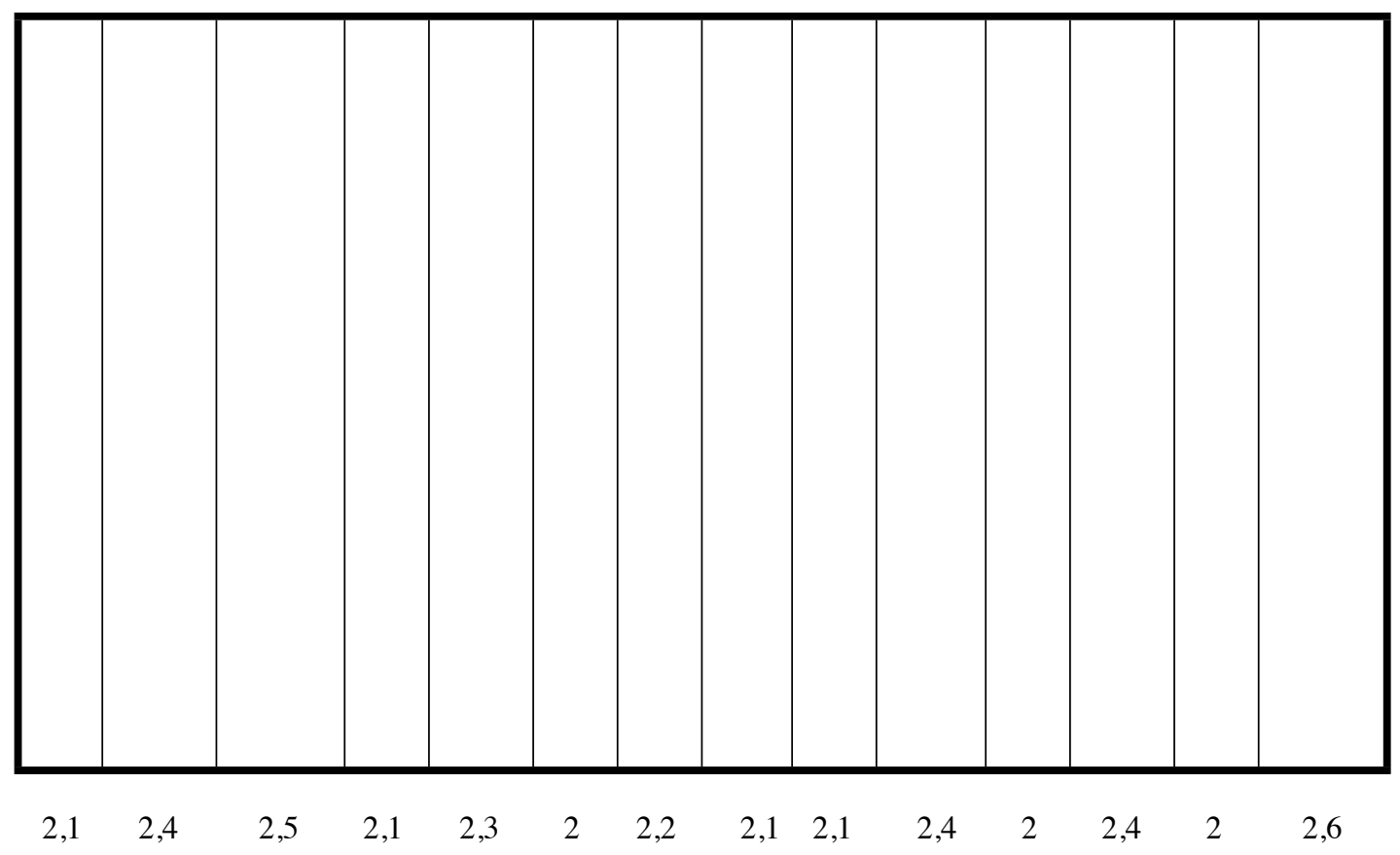

101 ZERDOUN BAT-YEHOUDA (1997): 2-10. Otros autores españoles también han empleado esta metodología, aunque fuera del ámbito de la musicología, como es el caso de GASCÓN URÍS (2003): 349-375. 
Una vez tomadas las medidas de los corondeles de todos los manuscritos analizados en esta investigación, se ha observado que en unos pocos las medidas eran muy similares entre los corondeles, frente al resto que eran más dispersas. El caso de la Salve a 10, el que aquí se expone, aglutina la gran parte de los manuscritos analizados, por lo que se ha expuesto como ejemplo significativo.
Las medidas entre los corondeles indican, además del color del papel (más ocuro o más claro), su grosor y su resistencia, que la calidad de las planchas de papel empleada por Diego Durón eran de una calidad media-baja. Por esa razón, algunos de los manuscritos necesitan en la actualidad una urgente restauración. En el siguiente ejemplo se puede observar el estado de conservación de algunos manuscritos.

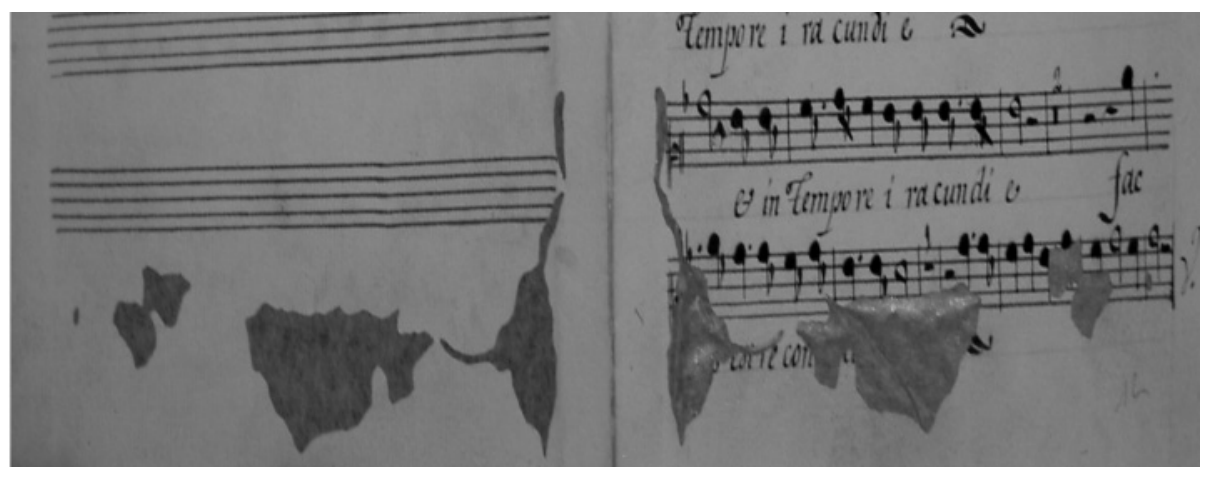

\subsubsection{Tipología de las marcas de agua en los manuscritos de Diego Durón de Ortega}

Las marcas de agua analizadas en el archivo de la catedral de Las Palmas de Gran Canaria presentan diversas tipologías en función de los modelos establecidos por Briquet, Bofarull y Sans, Churchill, Heawood y Picard ${ }^{102}$. Las filigranas recogidas pertenecen a:

1. Círculos: La familia de los "círculos" (tipo tres círculos) es muy frecuente en el archivo de la catedral y en el del resto de la península ibérica ${ }^{103}$. Éste tipo de familia de filigranas proviene de Italia, concretamente de Génova, aunque posteriormente desarrollado en Venecia y Lombardía, e imitados en Francia y España.

Según Gaudricault ${ }^{104}$ esta marca de agua se conoce como "tres círculos o escudo de Génova". El nombre "Génova" indica bastante el origen, y la marca parece ser una forma simplificada de las armas de la ciudad que llevan una cruz latina sobre un escudo soportado por dos grifos y dos círculos encima. Este papel se elaboró masivamente en los

102 BRIQUET (1968). CHURCHILL (1935). HEAWOOD (1950). PICCARD (1970). BOFARULL Y SANS (1959).

103 En el archivo de "El Museo Canario" también se encuentran diversas obras autógrafas de Diego Durón las cuales han servido para el estudio de la filigrana de los manuscritos.

104 GAUDRICAULT (1995): 59-60. molinos de los alrrededores de la ciudad de Génova: Fabriche, Mele, Crevari, Arenzano, Cogoleto, Varazze, Pegli y principalmente, Voltri.

El gran consumidor fue el mercado español y por esa razón fue imitado por los papeleros franceses para captar el mercado de la América española, aunque en los mercados de Périgord también se imitaban marcas de papel inglés y holandés. Los papeleros de la Provenza no tardaron en imitar esta marca y se menciona el proceso de fabricación del papel de tres círculos en un contrato de un molino papelero cerca de Marsella en 1635.

Son abundantes las referencias documentales durante el siglo XVIII a esta fabricación francesa de papel de Génova para exportar a España y las Indias españolas. En 1750, cerca de Pau se fabricaba papel florete de primera y segunda suerte, y el llamado trasse, marcados a la manera de Génova, destinados para escribir, imprimir y para envolver con destino a España y sus colonias. Hay documentación de que este papel llegaba en grandes partidas, a veces defectuoso, por lo que se aconsejaba revisar los fardos en la oficina de control de Bayona antes de partir para los puertos de Cádiz, Puerto de Santa María y Sevilla.

En España se intentó fabricar papel genovés, sinónimo de calidad. Muchos papeleros italianos se establecieron en España y mediante leyes, ordenanzas, prohibiciones, el estado español intentó suprimir esa dependencia que tenía del papel de Génova, tanto para el mercado interior como para las colonias. A mediados del siglo XVIII, Cataluña logró aumentar la producción, a la par que proliferó la creación de 
nuevos molinos papeleros en Valencia y en otras regiones para abastecer de papel de calidad a la Península y sus colonias ${ }^{105}$.

Dentro de la familia de los círculos se han observado diversas tipologías:

\subsection{Rematados por una corona}

Esta marca de agua o filigrana presenta un escudo unido a la parte superior por corona y en la inferior con dos círculos con diseños. De esta filigrana se han encontrado dos variantes que, debido a sus semejanzas, puede que sean del mismo molino. Esta misma tipología de marcas de agua se han observado en las obras de los maestros de capilla de la Comunidad Valencia, concretamente en la catedral de Orihuela en las obras del compositor Matías Navarro ${ }^{106}$.

\subsection{Rematados por una cruz}

Esta marca de agua está rematada por una cruz y con una media luna en su interior. Esta media luna clarifica su influencia italiana que se extendió en centroeuropa y que se amplió a tres medias lunas en los diseños de las filigranas. Este tipo de diseño fue muy utilizado en Italia por los fabricantes de papel y posteriormente los austriacos lo tomaron como moda, comprando primeramente el papel en Italia y posteriormente copiando el diseño ${ }^{107}$. El dibujo de la luna completa y de las estrellas era muy típico dentro de la cultura otomana cuyo significado espiritual, religioso o sagrado en su cultura estaba claramente generalizado. Durante el barroco y parte del clasicismo las marcas de agua italianas poseían ya de una manera casi generalizada estos diseños pero claramente con otro significado. El dibujo de las tres lunas traía implícito una alta calidad del papel. Por esta razón, el uso de "tre lune" como marca de agua, llevaba consigo una elaboración muy concreta de la pasta con la que se realizaba el papel y un mejor acabado. De esta manera, los manuscritos italianos presentan un papel mucho más delgado que el alemán, que es mucho más grueso y que a su vez dificulta mucho la observación de la filigrana.

Una gran cantidad de papel que se compraba en Italia y, que después se empleaba en centroeuropa, provenía principalmente de Venecia y de Lombardía ${ }^{108}$, distribuyéndose

105 BALMEDA (1999): 274-275.

106 ROMERO NARANJO; y BILBAO RIGUERO (2009): 9.

107 BROWN (1978). Véase especialmente el apéndice final con el catálogo completo de marcas de agua.

108 TYSON (1992): 60-62. también en España a través de los importantes puertos de Valencia y Barcelona.

2. Animales: El emplo de animales es también muy típico en la penísula ibérica. En la catedral de Las Palmas de Gran Canaria se han observado diversos tipos de animales, apareciendo en unos casos un becerro y en otros un buey.

3. Escudos: Sólo se ha observado una marca de agua con un escudo y una flor de lis en su interior y su procedencia es holandesa, según el catálogo de Churchill.

4. Picador: Diseño bastante típico de España, que se encuentra normalmente en el sur de la península ibérica y en Madrid, según Bofarull y Sans ${ }^{109}$. Según este autor esta marca de agua se comenzó a emplear en los últimos años del siglo XVII y principios del siglo XVIII. Esta filigrana se empleó mucho posteriormente en el sur de España (Cádiz), en Italia (Palermo, Génova) e incluso en Latinoamérica (Paraguay) ${ }^{110}$.

\subsubsection{Las marcas de agua gemelas en los manuscritos de Diego Durón. El sistema circunmétrico}

En el transcurso del análisis de las marcas de agua se ha observado en las filigranas correspondientes a los tres círculos, que aparecen marcas de aguas gemelas. Estas marcas de aguas gemelas aparecen en un mismo manuscrito, es decir, dos marcas de agua que aparentemente son la misma filigrana, pero contienen pequeñas diferencias.

Esta causa se debe a que el dibujo o matriz de la filigrana se relizaba normalmente a mano, en alambre, y se solía hacer por parejas. Debido a su método de fabricación se solía trabajar manual e independientemente, por lo que daba marcas distintas. Es por ello que no puede haber dos filigranas idénticamente iguales, por lo que si se encuentran dos filigranas iguales responderán a la misma forma y casi con total seguridad habrán salido del mismo molino papelero con un intervalo de tiempo relativamente corto, por más que aparezcan en manuscritos muy alejados entre sí geográficamente.

Alan Tyson ${ }^{111}$ ideó un sistema para identificar marcas de agua gemelas, que se denomina sistema selenométrico y

109 BOFARULL Y SANS (1959): 38. Véase también el catálogo de HEAWOOD, Edward: Watermarks... especialmente las filigranas 3467 hasta la 3482

110 HEAWOOD (1950): 141.

111 TYSON (1992): 60-61. 
que posteriormente también se ha empleado para las filigranas de Marianna Martines ${ }^{112}$. Inspirado sobre el procedimiento de Alan Tyson se procedido a la creación de otro sistema para las marcas de agua gemelas con tres círculos bautizado en esta investigación como "circunmétrico". Las mediciones realizadas se han articulado de la siguiente manera:

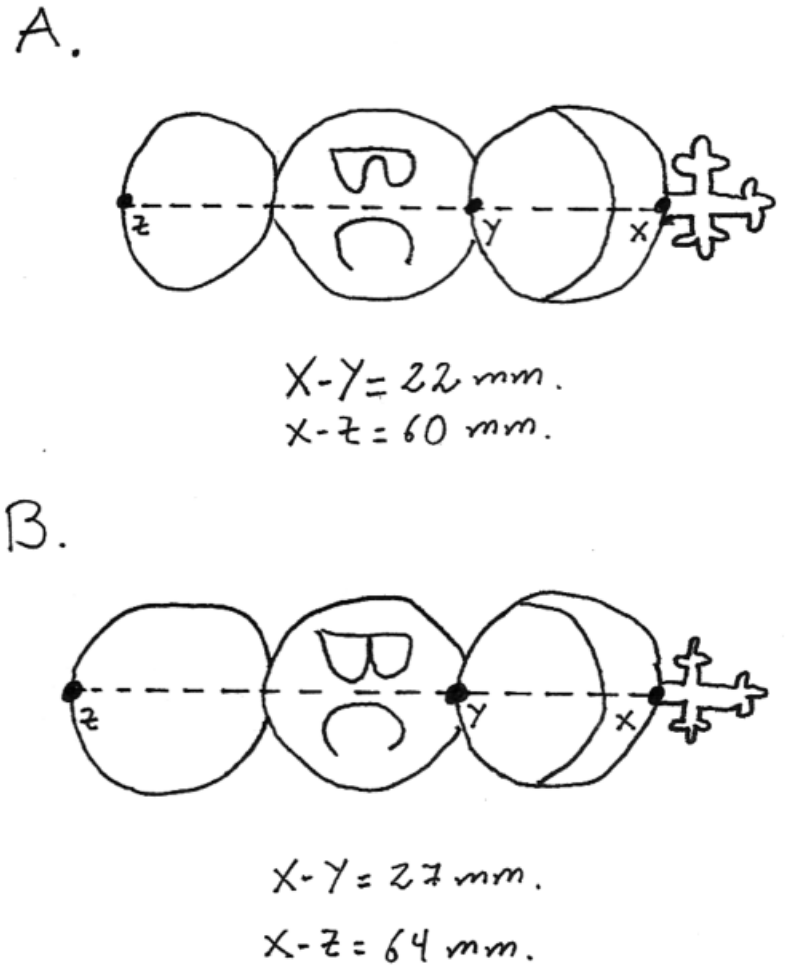

Si se elaboran las mediciones en función de X, Y, Z se puede observar con facilidad si las marcas de agua son gemelas y a su vez si las filigranas coinciden en el diseño y medida. Este sistema ayuda a la clasificación de marcas de agua gemelas, que en este caso ha clarificado el manuscrito Miserere de eccos, a 14 voces.

112 ROMERO NARANJO (2002): 340 -341.

\subsubsection{Datación de los manuscritos en función de las mar- cas de agua}

- Laudate dominum omnes gentes (B/V-7):

El tipo de papel que presenta esta obra es más oscuro y a su vez mucho más duro que muchos de los manuscritos consultados. La marca de agua de la obra Laudate Dominum omnes gentes proviene de Holanda, concretamente de Ámsterdam, y está fechada por Churchill en 1702, catalogada como la marca de agua $\mathrm{n}^{\circ} 424^{113}$. Remarca Churchill que la ley francesa de 1688 regulando la manufactura del papel ordenaba que las iniciales del nombre y apellidos del papelero debían ser añadidas en cada plancha de papel. Está demostrado que el arte del papel francés floreció a finales del siglo XVII y comienzos del siglo XVIII, por lo que Francia suministró también a otros países, aunque la industria declinó a mediados de siglo. A pesar de ello, numerosos países adoptaron o copiaron muchos diseños de marcas de agua como el de la "flor de lis" como fue el caso de Holanda e Inglaterra. Por esa razón en la contramarca se observan las iniciales "IHS" certificando su origen holandés. En la marca de agua, que posee el escudo y la flor de lis se observan las iniciales WR que provienen de Wendelin Riehel el cual las utilizaba desde 1585. La marca con el monograma WR continua después de la muerte de Wendelin Riehel al ser utilizada por sus sucesores, debido a la reputación de su calidad hasta 1742 . Heawood presenta 40 modelos con estas letras (n. 1721 y ss).

A continuación se puede ver en una fotografía el diseño original de la filigrana en el manuscrito.

113 CHURCHILL (1935): 19-42. CCCXVIII, filigrana $n^{\circ} 424$. Esta marca de agua está fechada por Churchill en 1702 aprox, en Holanda. 


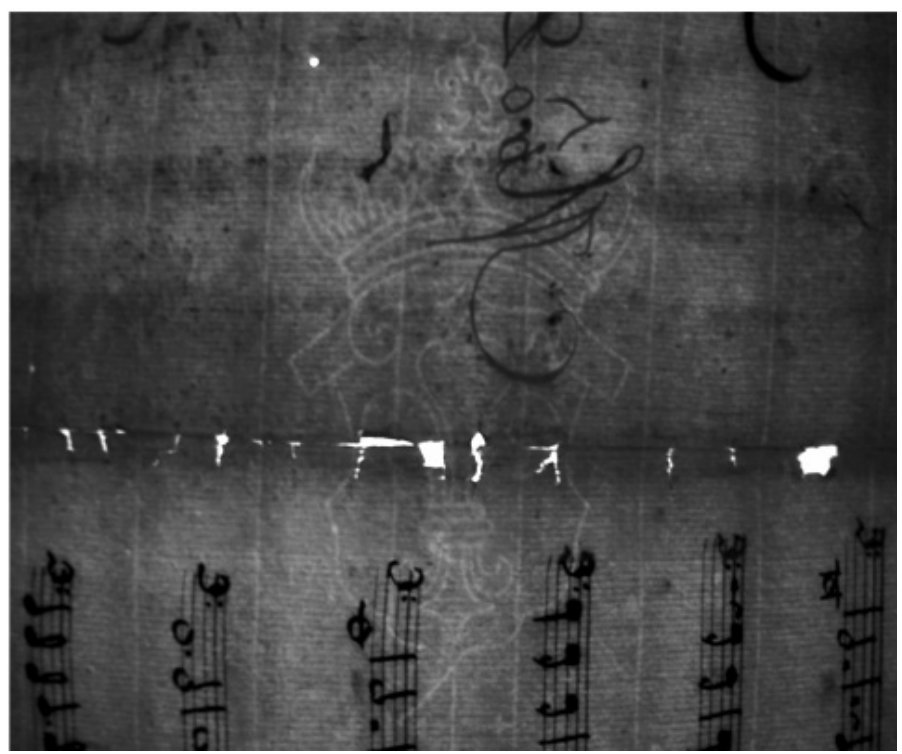

Este tipo de marca de agua también se ha observado en diversos manuscritos de Diego Durón, no sólo para música escrita en latín, sino en romance. Por ello, aquí queda constancia de la llegada de resmas de papel no sólo españolas, sino también de diversas partes de Europa, como es éste caso que procede de Holanda.

El dibujo de la filigrana es el siguiente:

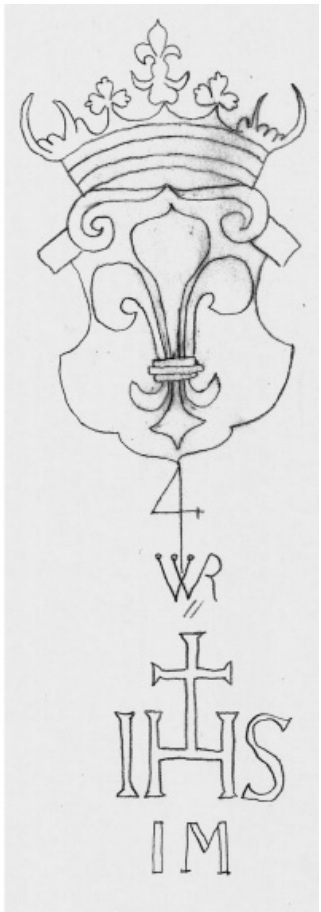

- Miserere de eccos (B/IV-2).

El Miserere de eccos contiene diversas marcas de agua pero todas con "tres círculos" y con marcas de agua gemelas.

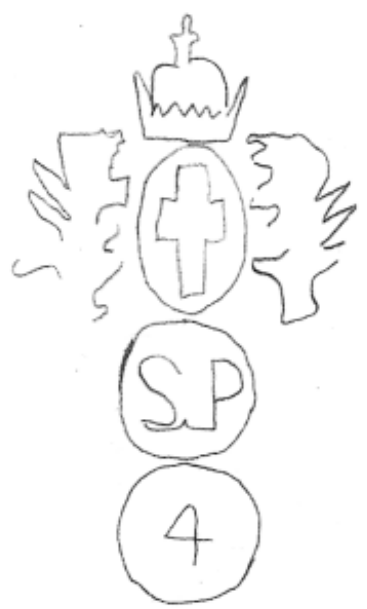

Esta primera marca de agua pertenece a la parte instrumental del clavicordio y está fechada por Heawood como posterior a $1710^{114}$.

114 HEAWOOD (1950): 43, pl. 119. 


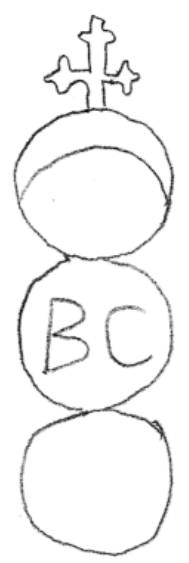

Esta segunda marca de agua procede de las voces y está fechada por Heawood en $1726^{115}$.

- Salve a 10 (B/VII-10)

La Salve a 10, posee una marca de agua de un toro datada en el año 1700, con la figura $\mathrm{n}^{\circ} 172$ según Bofarull y Sans ${ }^{116}$. El diseño de la filigrana es el siguiente:

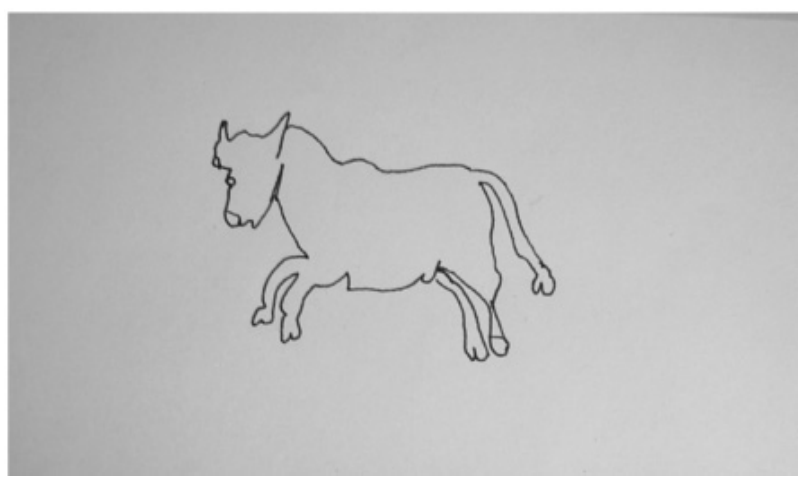

De la misma manera, también aparece la filigrana denominada "picador" en varias partes vocales, que según Heawood, y Bofarull y Sans, se comenzó a emplear en el útimo decenio del siglo XVII y principios del siglo XVIII. La filigrana exacta que aparece en el manuscrito no aparece en los catálogos de los autores mencionados aunque, posiblemente, esté fechada, como muy tarde, en los primeros años del siglo XVIII.

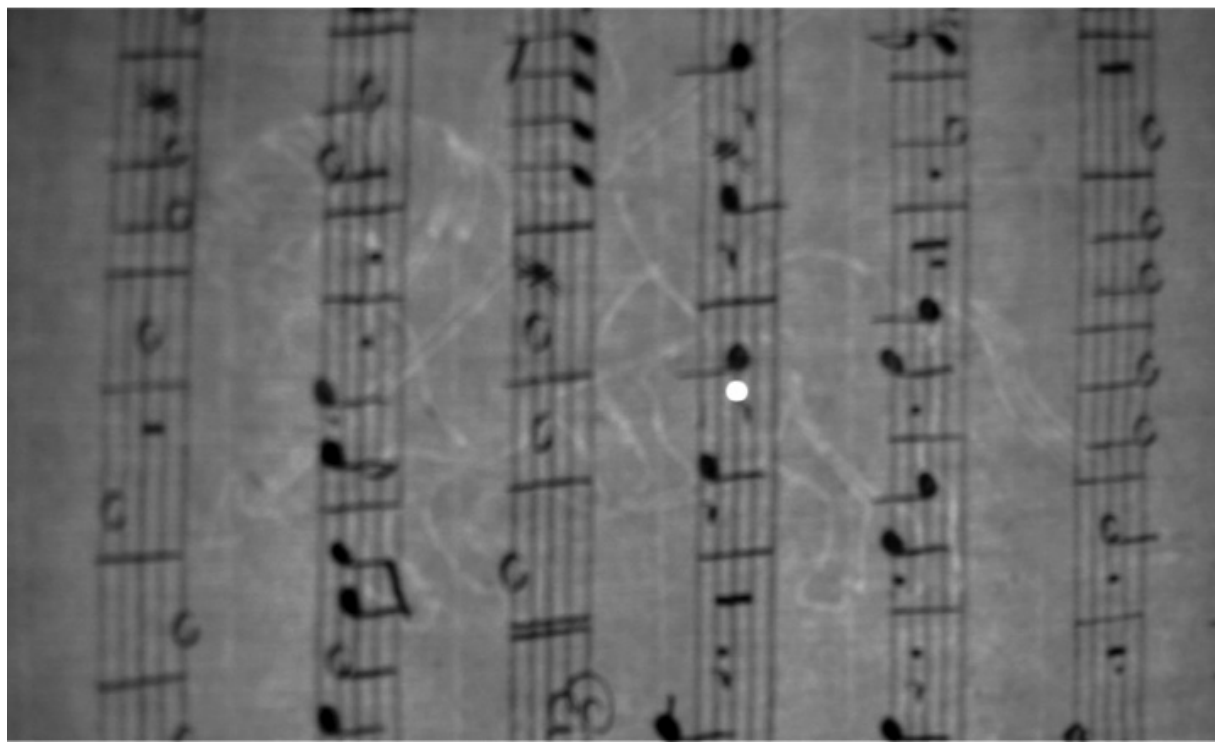

115 HEAWOOD (1950): 52, pl. 48, filigrana $\mathrm{n}^{\circ} 286$.

116 BOFARULL Y SANS (1959): 49, véase la marca de agua con el número 172. 
- Ecce sacerdos magnus (B/VII-13):

La marca de agua de este manuscrito es un animal, una especie de toro que está fechado por Bofarull y Sans en 1790 y procede originalmente de Barcelona ${ }^{117}$.

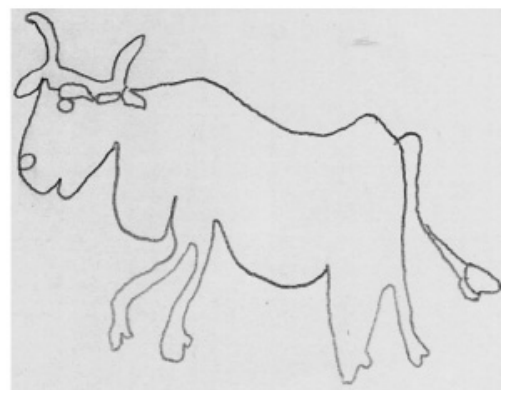

\subsubsection{Estudio rastrológico de los manuscritos}

Como complemento al estudio de las marcas de agua se añade un estudio de tipo rastrológico, que ofrece datos que ayudarán a clasificar por períodos las obras de Diego Durón de Ortega. Para este apartado se ha tomado en cuenta la metodología de diversos especialistas como Wolff ${ }^{118}$, Wolf $^{119}$, Everet ${ }^{120}$ y Tyson ${ }^{121}$, para poder obtener unidad de criterios. En el siguiente ejemplo se puede observar un ejemplo de rastrum (la figura de la derecha) según la publicación de Edward Knight ${ }^{122}$ :
117 BOFARULL Y SANS (1959): 49, véase la marca de agua con el número 177.

118 WOLFF (1963): 80-92.

119 WOLF y WOLF (1990): 237-291.

120 EVERETT, Paul (1983): 135-158.

121 TYSON (1987).

122 KNIGHT (1880): 1501.

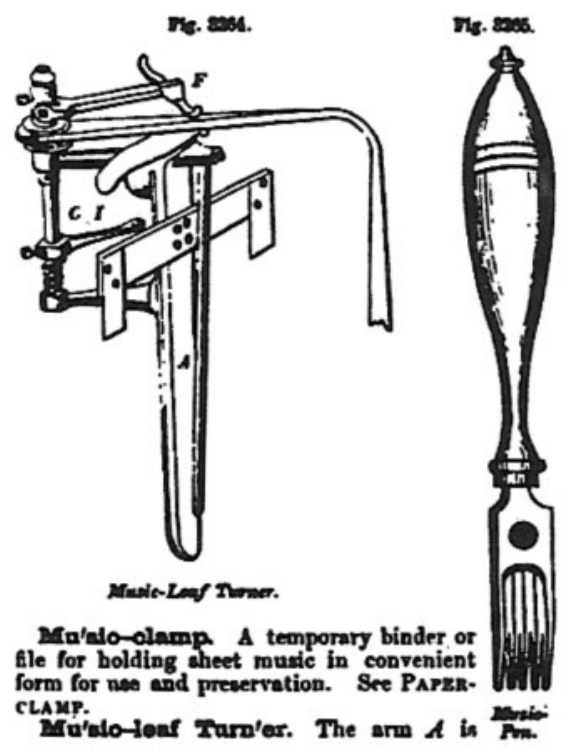

En función de los autores anteriormente citados, se han tomado como referencia los siguentes aspectos fundamentados en los manuscritos:

- La distancia entre un sistema y otro que todos los autores unifican con la denominación DS.

- La distancia entre una línea y otra del pentagrama que todos los autores unifican con la denominación DL.

- La distancia entre las cinco líneas del pentagrama que todos los autores unifican con la denominación SS.

- La distancia total de todos los sistemas (la cuadratura de los pentagramas) que todos los autores unifican con la denominación TS.

- El largo del pentagrama que todos los autores unifican con la denominación $\mathbf{L S}$.

Los resultados que se obtuvieron fueron muy interesantes porque las medidas variaban en función de la datación cronológica de los manuscritos autógrafos. En el cuadro sinóptico que a continuación se presenta se pueden observar las diferencias: 


\begin{tabular}{|c|c|c|c|c|c|c|c|c|c|}
\hline $\begin{array}{c}\text { Manuscrito y } \\
\text { signatura }\end{array}$ & Ubicación & Papel & Copias & Sistemas & $T S^{123}$ & $\mathbf{L S}^{124}$ & $\mathbf{D S}^{125}$ & $\mathbf{D L}^{126}$ & $\mathbf{S S}^{127}$ \\
\hline $\begin{array}{c}\text { Miserere de } \\
\text { Eccos. } \\
\text { B/IV-2 }\end{array}$ & $\begin{array}{c}\text { Archivo de la } \\
\text { catedral de Gran } \\
\text { Canaria }\end{array}$ & & No & 7 & $311 \mathrm{~mm}$ & $290 \mathrm{~mm}$ & $150 \mathrm{~mm}$ & $3 \mathrm{~mm}$ & $15 \mathrm{~mm}$ \\
\hline $\begin{array}{c}\text { Ecce sacerdos } \\
\text { magnus } \\
\text { B/VII-13 }\end{array}$ & $\begin{array}{c}\text { Archivo de la } \\
\text { catedral de Gran } \\
\text { Canaria }\end{array}$ & & $\begin{array}{c}\text { Si. } \\
\text { Sólo se } \\
\text { conserva } \\
\text { una copia } \\
\text { y no el } \\
\text { original }\end{array}$ & 9 & $290 \mathrm{~mm}$ & $180 \mathrm{~mm}$ & $170 \mathrm{~mm}$ & $3 \mathrm{~mm}$ & $160 \mathrm{~mm}$ \\
\hline $\begin{array}{c}\text { Laudate } \\
\text { Dominus } \\
\text { gentes } \\
\text { B/V-7 } \\
\end{array}$ & $\begin{array}{c}\text { Archivo de la } \\
\text { catedral de Gran } \\
\text { Canaria }\end{array}$ & & No & 7 & $340 \mathrm{~mm}$ & $310 \mathrm{~mm}$ & $170 \mathrm{~mm}$ & $2,8 \mathrm{~mm}$ & $13 \mathrm{~mm}$ \\
\hline $\begin{array}{c}\text { Salve a } 10 \\
\text { B/VII-10 }\end{array}$ & $\begin{array}{c}\text { Archivo de la } \\
\text { catedral de Gran } \\
\text { Canaria }\end{array}$ & & No & 6 & $310 \mathrm{~mm}$ & $300 \mathrm{~mm}$ & $170 \mathrm{~mm}$ & $2,9 \mathrm{~mm}$ & $13 \mathrm{~mm}$ \\
\hline $\begin{array}{l}\text { Isti sunt } \\
\text { B/VII-13 }\end{array}$ & $\begin{array}{c}\text { Archivo de la } \\
\text { catedral de Gran } \\
\text { Canaria }\end{array}$ & & No & 8 & $290 \mathrm{~mm}$ & $175 \mathrm{~mm}$ & $200 \mathrm{~mm}$ & $3 \mathrm{~mm}$ & $12 \mathrm{~mm}$ \\
\hline $\begin{array}{c}\text { Nunc dimittis } \\
\text { B/V-5 }\end{array}$ & $\begin{array}{c}\text { Archivo de la } \\
\text { catedral de Gran } \\
\text { Canaria }\end{array}$ & & No & & $310 \mathrm{~mm}$ & $290 \mathrm{~mm}$ & $150 \mathrm{~mm}$ & $3 \mathrm{~mm}$ & $15 \mathrm{~mm}$ \\
\hline
\end{tabular}

\section{FIGURA DE DIEGO DURÓN. UNA INDIVIDUALIDAD HISTÓRICA EN EL PANORAMA BARROCO ESPAÑOL}

La figura de Diego Durón como maestro de capilla en la catedral de Las Palmas de Gran Canaria presenta una dualidad compositiva. Desde el punto de vista estilístico no le estaba permitido expresarse con una sonoridad que se saliera del sonido litúrgico solemne que los canónigos querían escu-

123 Total span.

124 Length of staff.

125 Distance between staves.

126 Distance between lines.

127 Stave span. char, al menos en las obras compuestas para el tren litúrgico, pero no en las obras paralitúrgicas como los villancicos que sustituían a los responsorios de Maitines. En las obras en romance se muestra otro tipo de soltura, siendo ésta menos encorsetada y con mayor libertad compositiva.

Cuando Diego Durón se incorpora a la catedral de Las Palmas de Gran Canaria, viene a ser el decimosexto maestro de capilla que contrata la catedral en tan sólo 76 años. Como consecuencia de ello, los músicos están acostumbrados a continuos cambios basados en las formas de organizar y preparar los oficios litúrgicos, dando lugar a continuos desajustes. En la siguiente tabla se puede observar el número de maestros de capilla que pasaron por la catedral y el período en que trabajaron. 


\begin{tabular}{|c|c|c|c|}
\hline Maestro de Capilla & $\begin{array}{c}\text { Estancia en la Catedral como } \\
\text { maestro de capilla }\end{array}$ & Procedencia & Estatus \\
\hline Francisco de la Cruz & $1600-1602$ & Península & Por oposición \\
\hline Francisco Visconti & 1602 & Italia & Por oposición \\
\hline Martín de Silos & $1602-1605$ & $\begin{array}{c}\text { Península - } \\
\text { Aragón }\end{array}$ & Maestro interino \\
\hline Gaspar Gómez & $1605-1607$ & Portugal & Por oposición \\
\hline Martín de Silos & $1607-1614$ & Aragón & Maestro interino \\
\hline Melchor Cabello & $1614-1616$ & Península - & Por oposición \\
\hline Juan Bautista Pérez & $1616-1625$ & Península & Maestro interino \\
\hline Medina & $1625-1631$ & Península & Por oposición \\
\hline Jerónimo Pérez Baylón & $1631-1638$ & Portugués & Por oposición \\
\hline Manuel de Tavares & $1645-1650$ & Península & Por oposición \\
\hline Francisco Redondo & $1650-1651$ & Península & \\
\hline Juan Macel & $1651-1661$ & Península & Por oposición \\
\hline Juan de Cuevas & $1661-1668$ & Navarra & Por oposición \\
\hline Miguel de Yoldi & $1669-1674$ & Portugués & Por oposición \\
\hline Juan de Figueredo Borges & $1674-1676$ & Gran Canaria & Maestro interino \\
\hline González Montañéz & $1676-1731$ & $\begin{array}{c}\text { Península - } \\
\text { Guadalajara }\end{array}$ & Por oposición \\
\hline Diego Durón & & \\
\hline
\end{tabular}

La figura de Diego Durón se puede considerar una individualidad histórica en su tiempo y espacio geográfico por diversos motivos:

1. Supo reorganizar un capilla de música que tras los continuos cambios de maestros de capilla tenía una total falta de autoridad ${ }^{128}$.

2. Creó una cantera de músicos isleños formados en la misma catedral y bajo sus directrices.

3. Conservó un ¿estilo propio ajeno? a las novedades que se realizaban en la península.

4. No aparecen variantes compositivas en función de los géneros litúrgicos, aportando así Diego Durón un estilo homogéneo que se va perfeccionando a lo largo de su trayectoria como maestro de capilla.

5. Integró en su música escrita en romance a personajes de la vida popular canaria y con un amplio uso de melodías populares.

128 Caben recordar los problemas ocurridos con Gaspar Gómez, Manuel Tavares, Francisco Redondo y Juan de Cuevas.
Diego Durón es el primer maestro de capilla que se preocupa de formar a una serie de músicos nativos para los cultos litúrgicos de la catedral de Las Palmas de Gran Canaria. Pero ante ello, surge la pregunta ¿cómo pudo realizar semejante "hazaña" partiendo de cero? La catedral poseía una buena estabilidad económica y podía costearse traer a músicos de la península, tanto de España como de Portugal (como fue el caso de Manuel de Tavares), pero el problema estaba en la permanencia de los mismos en las islas, que no era muy prolongada.

Diego Durón tenía como obligación formar en el arte de la música a los mozos de coro, pero su preocupación iba más allá. Los mozos de coro recibían clases particulares en la casa del maestro de capilla sin ser retribuidas por la catedral, dado que no se hace ninguna referencia a estos pagos en las actas capitulares ni en los libros de fábrica. De la misma manera no pasa por alto las ausencias de los músicos a los ensayos, penalizándolos económicamente cuando esto ocurre, o incluso por mal comportamiento.

Cuando los mozos de coro tienen el cambio de voz, en vez de despedirlos les obliga a aprender un instrumento durante ese período, empleándolos en la catedral con esa fun- 
ción. Ésa es la razón por la que manda comprar un violón, cornetas, un "tenorete", un arpa y chirimías para la catedral, tal y como consta en las actas capitulares.

La capilla de música de la catedral de Las Palmas de Gran Canaria obtuvo su momento más estable y productivo con la llegada del maestro de capilla Diego Durón. Por primera vez en su historia se estabilizó el régimen de músicos foráneos y se procuró la formación musical de los canarios para su posterior inclusión en la catedral. Dicha estabilidad estuvo condicionada por la tranquilidad de sus ciudadanos al no verse continuamente amenazados por los ataques piratas, siendo el último el protagonizado por el holandés Pieter Van der Does en 1599. A esto hay que añadirle la condición de puerto marítimo, que canalizó todo el comercio español en relación a América, que traía consigo mercaderes con bastante capital y una cantidad ingente de personas que estaban de paso en su marcha a América.

Debido a este trasiego tan amplio, Diego Durón contó con un número cuantioso de músicos, y supo filtrar a los músicos que entraban bajo su autoridad en la catedral mediante pruebas o una estricta formación. La Iglesia canaria, representada por la catedral y su cabildo, dio casi siempre su consentimiento a todas sus peticiones a la hora de contratar a nuevo personal para su capilla, por lo que pudo poseer una nutrida capilla en función de sus necesidades.

Esta investigación ha servido para establecer los criterios compositivos de sus obras policorales en latín y su relación con las actas capitulares. Se ha podido establecer cronológicamente cada una de sus obras, sirviéndonos de diversas metodologías para poder datar cada manuscrito.

El estudio de las obras policorales en latín servirá como base para futuros estudios sobre sus obras (tanto en latín como en lengua romance) que todavía no se han examinado, dado que el corpus compositivo de Durón es amplísimo. Las conclusiones de esta investigación prueban no sólo la cronología de las fuentes mediante su estilo musical y la datación de sus marcas de agua, sino la dualidad compositiva del maestro a la hora de componer obras en latín o en lengua romance.

\section{BIBLIOGRAFÍA}

Balmeda, José Carlos:"La filigrana de los tres círculos en la documentación malagueña del siglo XVIII", $A c$ tas del III Congreso Nacional de Historia del Papel en España. Valencia, Consellería de Cultura, Educacío i Ciéncia de la Generalitat Valenciana, 1999, $274-275$.

Bofarull y Sans, Francisco: Animals in watermarks. Hilversum-Holland, The paper Publications Society, 1959.
Briquet, Charles Moïse: Les Filigranes: Dictionnaire Historique des Marques du Papier des leur apparition vers 1282 jusqu'en 1600. (Facsimile of the 1907 ed.; Stevenson, Allan, ed.). 4 vols. Amsterdam, Paper Publications Soc., 1968.

Brown, Peter A.: Carlo D`Ordonez 1734 - 1786. A Thematic Catalog. Detroit, Detroit studies in music bibliography, 1978.

Bueno, Diego: Arte nuevo de enseñar a leer, escrivir y contar principes y señores. Zaragoza, Diego Gascón, 1690.

Churchill, William Algernon: Watermarks in paper in Holland, England, France, etc., in the XVII and XVIII centuries and their interconnection. Amsterdam, Menno Hertberger \& Co., 1935.

Everett, Paul: "The application and uselfulnes of "rastrology", with particular reference to early eighteenth-century Italian manuscripts". (Pascuale, M.D., ed.). Musica e filologia. Ferona, Edizioni della Societá Literari, 1983.

Ezquerro Esteban, Antonio: La música vocal en Aragón en el segundo tercio del siglo XVII: tipologías, técnicas de composición, estilo y relación música y texto en las composiciones de las catedrales de Zaragoza.Tesis doctoral, Barcelona, Universitat Autònoma de Barcelona, 1997. Especialmente, subcapítulo "Las marcas de agua".

Ezquerro Esteban, Antonio: Villancicos aragoneses del siglo XVII de una a ocho voces. Barcelona, Departamento de Musicología, Institución Milá y Fontanals, CSIC, col. "Monumentos de la Música Española, LV”, 1998.

Gascón Urís, Sergi: "Las filigranas de papel de la encomienda hospitalaria de Vallfogona de Riucorb. (2 $2^{\mathrm{a}}$ parte)", Actas del V Congreso Nacional de Historia del Papel en España. Sarrià de Ter (Girona), CCG Ediciones, 2003, pp. 349-375.

Gaudricault, Raymond: Filigranes et autres caracteristiques des papiers fabriqués en France au XVIIe. et XVIIIe. Siècle. Paris, CNRS, 1995.

Heawood, Edward: Watermarks, Mainly of the 17th and 18th Centuries. Hilversum, Holland, Paper Publications Society, 1950.

Hunter, Dard: Papermaking. Through eighteen Centuries. New York, editorial, 1930.

Icíar, Juan de: Recopilacion subtilissima intitulada ortographia pratica. Zaragoza, Bartolomé de Nájera, 1548.

Knight, Eduard Henry: Knight's American Mechanical dictionary. A Descriptions of Tools, Instruments, Machines, Processes, and Engineering; History of Inventions; General Technological Vocabulary; and Digest of Mechanical Appliances in Science and the Arts. Boston, Houghton, Osgood \& Co., 1880. 
Luxán Meléndez, Santiago: La industria tipográfica en Canarias 1750-1900. Balance de la producción impresa. Gran Canaria, Ediciones del Cabildo Insular de Gran Canaria, 1994.

Mut Calafell, Antonio: "Fórmulas españolas de tintas caligráficas de color azul y rojo...", Actas del V Congreso Nacional de Historia del Papel en España. Sarrià de Ter (Girona), CCG Ediciones, 2003, 473-475.

Mut Calafell, Antonio: "Fórmulas españolas de la tinta caligráfica de color verde (Siglos XVI-XIX)", Actas del V Congreso Nacional de Historia del Papel en España. Sarrià de Ter (Girona), CCG Ediciones, 2003, 585-596.

Piccard, Gerhard: Turm Wasserzeichen. Findbuch III of Die Wasserzeichen Piccard im Haupstaatsarchiv Stuttgart. Stuttgart, Verlag W. Kohlhammer, 1970.

Pope, Isabel: El villancico polifónico en el Cancionero de Uppsala. México, Colegio de México, 1944.

Romero Naranjo, Francisco Javier; y Bilbao Riguero, Joxe: Aportación al archivo musical de la S. I. Catedral del Salvador de Orihuela... Alicante, Diputación de Alicante, 2009, 7-9.

Romero Naranjo, Francisco Javier: "Fuentes de Marianna Martines en el archivo prusiano de Berlín. El Miserere a 4 voci concertante, 1768", Nassarre, XVIII/1-2 (2002), 340-341.

Siemens Hernández, Lothar: "Durón de Ortega, Diego", Diccionario de la Música Española e Hispanoamericana. Vol. 4. Madrid, SGAE, 1999, 572-575.

Siemens Hernández, Lothar: Ya rompen sus velos. Villancico de Navidad a 8 con chirimías y bajo continuo (1690). Madrid, Sociedad Española de Musicología, 1984.

Torre Champasaur de Trujillo, Lola de la:"La capilla de música de la catedral de Las Palmas y el compositor D. Sebastián Durón”, El Museo Canario, $85-89$ (1963), 39-49.

Torre Champasaur de Trujillo, Lola de la: "El Archivo de Música de la Catedral de Las Palmas I", El Museo Canario, 89-92 (1964), 181-242.
Torre Champasaur de Trujillo, Lola de la: "El Archivo de Música de la Catedral de Las Palmas II", El Museo Canario, 93-96 (1965), 147-203.

Torre Champasaur de Trujillo, Lola de la: "Documentos sobre la música en la catedral de las Palmas (16611680)", El Museo Canario, 54 (1999), 830-831.

Torre Champasaur de Trujillo, Lola de la: "Documentos sobre la música en la catedral de las Palmas (16811700)", El Museo Canario, n. ${ }^{\circ}$ (2000), 352-422.

Torre Champasaur de Trujillo, Lola de la: "Documentos sobre la música en la catedral de las Palmas (17211740)", $\mathrm{n}^{\circ}$ (2002), 340-409.

Tschudin, Peter F.: Grundzüge der Papiergeschichte. Stuttgart, Hiersemann, 2002.

Tyson, Alan: Mozart: Studies of the Autograph Scores. Cambridge, MA, Harvard University Press, 1987.

Tyson, Alan: Wolfgang Amadeus Mozart. Neue Ausgabe sämtlicher Werke. Wasserzeichnen - Katalog. Kassel, Bärenreiter, 1992 (X/ 33/ Abteilung 2, Abbildungen, $\mathrm{X}-\mathrm{XI})$.

Wolf, Eugene K.; y Wolf, Jean K.: "Rastrology and Ist use in eighteenth-century manuscript studies". (Wolf, E. K.; y Roesner, Edward. H., eds.). Studies in Musical Sources and Style: Essays in Honour of Jan LaRue. Madison, A-R Editions, 1990, 237-291.

Wolff, Christoph: "Die Rastrierung in den Originalhandschriften Joh. Seb. Bachs und ihre Bedeutung für die diplomatische Quellenkritik", Festschrift für Friedrisch Smend zum 70. Geburstag. Berlin, Merseburger Berlin Verlag, 1963, 80-92.

Zerdoun Bat-Yehouda, Monique: Les papiers filigranés des manuscripts Hébreux datés jusqu'à 1450 conservés en France et en Israël. Brepols, Turnhout, 1997, 2-10.

Zerdoun Bat-Yehouda, Monique: Les encres noires au Moyen Age (jusqu'à 1600). Paris, C.N.R.S., 1983.

Recibido: 12.04 .2016

Aceptado: 03.05.2016 